\title{
ASSESSMENT OF SNOW-ATMOSPHERE FORCING DURING CENTRAL IDAHO ATMOSPHERIC RIVERS
}

\author{
by \\ William Rudisill
}

\author{
A thesis \\ submitted in partial fulfillment \\ of the requirements for the degree of \\ Master of Science in Hydrologic Sciences \\ Boise State University
}

August 2018 
(C) 2018

William Rudisill

ALL RIGHTS RESERVED 
BOISE STATE UNIVERSITY GRADUATE COLLEGE

\title{
DEFENSE COMMITTEE AND FINAL READING APPROVALS
}

\author{
of the thesis submitted by
}

William Rudisill

Thesis Title: Assessment of Snow-Atmosphere Forcing During Central Idaho Atmospheric Rivers

Date of Final Oral Examination: 27 April 2018

The following individuals read and discussed the thesis submitted by student William Rudisill, and they evaluated the presentation and response to questions during the final oral examination. They found that the student passed the final oral examination.
Alejandro N. Flores, Ph.D.
Chair, Supervisory Committee
Hans-Peter Marhall, Ph.D.
Member, Supervisory Committee
James P. McNamara, Ph.D.
Member, Supervisory Committee
Matthew J. Kohn, Ph.D.
Member, Supervisory Committee

The final reading approval of the thesis was granted by Alejandro N. Flores, Ph.D., Chair of the Supervisory Committee. The thesis was approved by the Graduate College. 


\section{ACKNOWLEDGMENTS}

I would like to thank my family and friends for their continued encouragement and support. 


\begin{abstract}
Atmospheric Rivers (AR) are globally occuring weather features and the primary mechanism through which water vapor moves from the tropics and subtropics towards the mid-latitudes, doing so at rates comparable to the world's largest terrestrial rivers. AR that encounter mountains often cause extreme precipitation in the form of rain and snow, high winds, and flooding in many watersheds. They account for as much as $20-30 \%$ of cool season precipitation in the central Idaho Mountains. In the Northern Hemisphere, seasonal snow cover during Winter and Spring months is the most variable land surface component in space and time, and acts on the fluxes of energy and mass into the atmospheric system. To date, there has been little effort to understand how the land surface snow cover states prior to and during the arrival of ARs, acting on the surface mass and energy balance, impact the onset, extent, and evolution of precipitation accumulation during AR events. Using a high resolution coupled land-atmosphere model, I examine the sensitivity of the precipitation regime and atmospheric energy balance to an ensemble of realistic snowcover states during a March 1998 AR case study in central Idaho. The results indicate that snow cover forcing 1) causes reductions of shortwave radiation and sensible heating that are balanced by atmpospheric energy transport, 2) increases atmospheric static stability, and 3) modifies the distributions of total accumulated precipitation by as much as $10 \mathrm{~mm}$.
\end{abstract}




\section{TABLE OF CONTENTS}

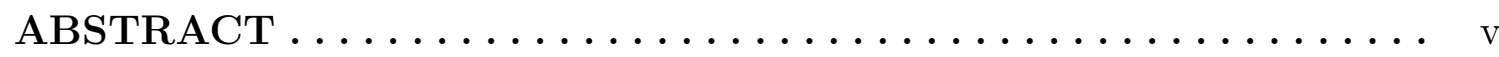

LIST OF TABLES ....................... viii

LIST OF FIGURES ...................... ix

LIST OF ABBREVIATIONS $\ldots \ldots \ldots \ldots \ldots \ldots \ldots \ldots \ldots \ldots$ xi

1 Conceptual Outline ....................... 1

2 Role of Snow-Atmosphere Interactions in central Idaho Atmospheric

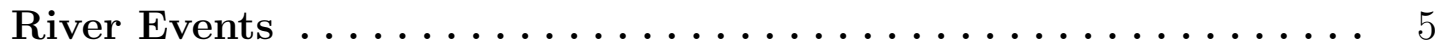

2.1 Literature Review of Snow Atmosphere Interactions . . . . . . . . . 5

2.1.1 Unique Physical Properties of Snow . . . . . . . . . . . . 7

2.1.2 Examples of Snow-Atmosphere Interactions . . . . . . . . . . 8

2.1.3 Synopsis of Literature . . . . . . . . . . . . . . . . . . . 12

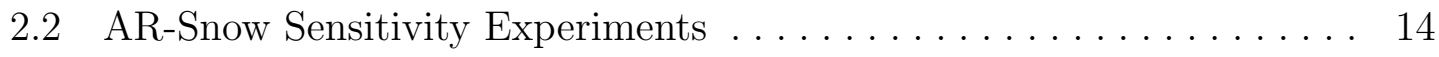

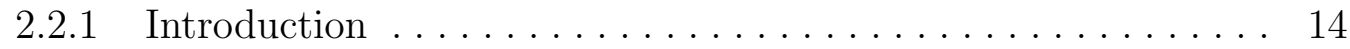

2.2 .2 Methods ............................. 14

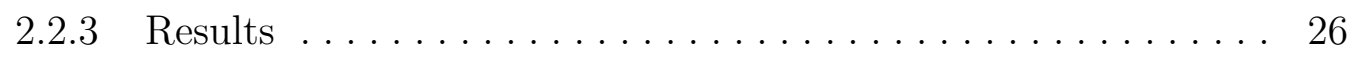

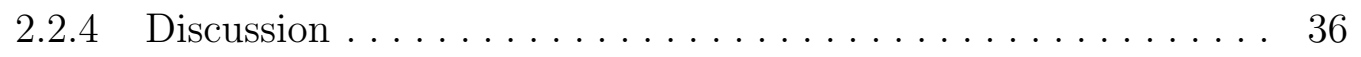




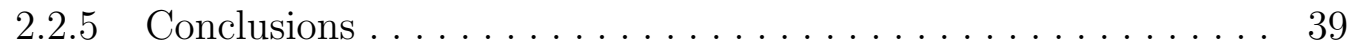

2.3 Summary .......................... 40

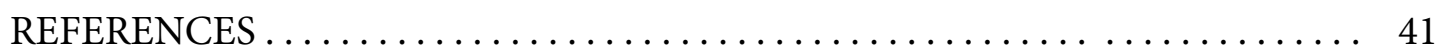

APPENDIX A Atmospheric River Literature Review ........... 49

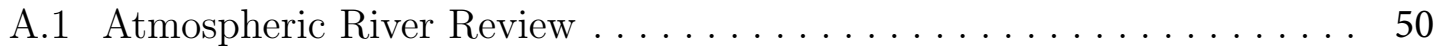

A.2 Atmospheric River Detection ................... 53

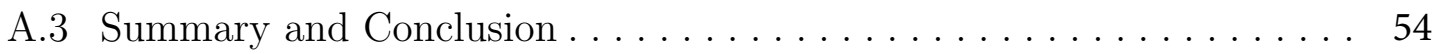




\section{LIST OF TABLES}

2.1 Accumulated Precipitation summed across the entirety of domain 2 for the control run (meters) and \% of the control precipitation for

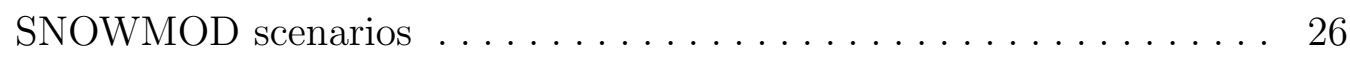

viii 


\section{LIST OF FIGURES}

2.1 WRF Model Domains. The outer domain has a $3 \mathrm{~km}$ spatial cell resolution, and the inner cell has a $1 \mathrm{~km}$ resolution . . . . . . . . . . . 15

2.2 Experimental Design. For the 1998 AR event, 5 total experiments are performed: 'No-Snow', 'Low-Snow', 'Medium-Snow', 'High-Snow' initial conditions, as well as a control run with unmodified initial

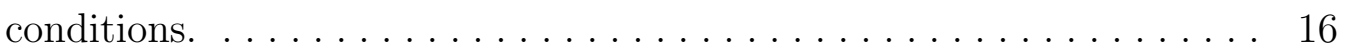

2.3 WRF Parameterization options used for this research. . . . . . . . . 17

2.4 Initial Snow Covered Fraction maps. Clockwise from top left: No Snow (NS), Medium Snow (MS), Low Snow (LS), High Snow (HS) . . 19

2.5 Distribution of mean domain wide Snow Water Equivalent (blue) and Snow Covered Area (red) by day-of-water year between 1986 and 2016. The solid lines are the median, dotted lines the mean, and shaded regions are the interquartile range $\ldots \ldots \ldots \ldots \ldots \ldots$

2.6 The components of the atmospheric energy budget. Refer to text for

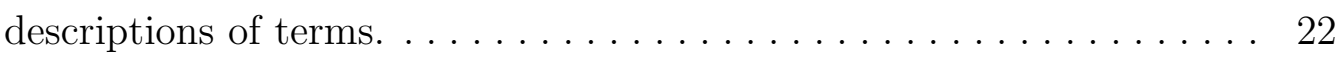

2.7 Difference in total accumulated snow and graupel (liquid equivalent) between SNOWMOD scenarios (clockwise from top left) NS, LS, HS,

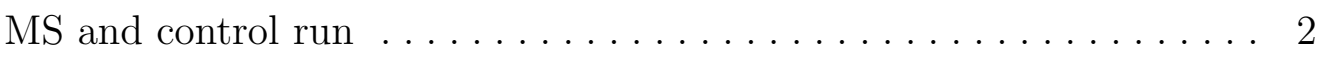


2.8 Difference in total accumulated rain between SNOWMOD scenarios (clockwise from top left) NS, LS, HS, MS and control run . . . . . . . 28

2.9 Average horizontal energy transport $(-\nabla \cdot \mathbf{f})$ for SNOWMOD scenarios (clockwise from top left) NS, LS, HS, MS. Units are $w / m^{2} \ldots \ldots \ldots 30$

2.10 Top of Atmosphere Radiation $\left(F_{T O A}\right)$ flux for SNOWMOD scenarios (clockwise from top left) NS, LS, HS, MS. Units are $w / m^{2} \ldots \ldots \ldots 31$

2.11 Surface Energy Balance $\left(F_{S F C}\right)$ flux for SNOWMOD scenarios (clockwise from top left) NS, LS, HS, MS. Units are $w / m^{2} \ldots \ldots \ldots \ldots$

2.12 Domain Energy Budget Flux Terms for the 1998 AR event . . . . . . . 33

2.13 The difference between scenario HS and NS Energy Budget Terms versus $-\nabla \cdot \mathbf{f}$. Grid cells where there is no difference in initial snow covered area between HS and NS are red; Grid cells with higher initial snow in the HS scenario are blue. . . . . . . . . . . . . . 35

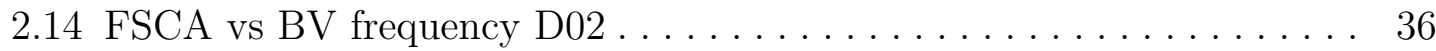

A.1 AR Identification Criteria, based on Guan et al (2015) . . . . . . . . . 54

A.2 A selection of AR events modeled in this thesis. Axes are lat/lon coordinates, color shading corresponds with the magnitude of IVT, and the arrows indicate IVT direction. Values in box refer to mean values of IVT, object length, wind direction, and wind direction variance. The black line is the object centerline. . . . . . . . . . . . 56 


\title{
LIST OF ABBREVIATIONS
}

\author{
AR - Atmospheric River \\ WRF - Weather Research and Forecasting Model \\ CFSR - Climate Forecast System Reanalysis \\ IVT - Integrated Vapor Transport \\ IWV - Integrated Water Vapor \\ LSM - Land Surface Model \\ SCA - Snow Covered Area \\ SWE - Snow Water Equivalent
}




\section{CHAPTER 1}

\section{CONCEPTUAL OUTLINE}

Why does it rain or snow? There are three key ingredients: upward motion of air, dust or aerosols that act as condensation nuclei, and sufficient water vapor to condense and form clouds. Any atmospheric instability that produces upward, vertical motions of air are called 'storms'. They can take many forms and are commonly caused by convection, the large scale interactions between air masses of different pressures (frontal systems), or the forced movement of air over tall mountain barriers ('orographic' uplift). These three mechanisms are not mutually exclusive, and in fact occur simultaneously in many instances. Differential heating between mountain slopes can initiate convection and thunderstorms. Likewise, orographic uplift can be enhanced by the co-occurrence of frontal uplift. Orographic precipitation plays a vital role in the hydrologic system across the globe, including the Western United States. The orographic precipitation signature is written into the ecology - dry desert regions are found on the leeward sides of large mountain ranges, such as the Sierra or Chilean Andes. Generally, precipitation totals and rates increase with increasing topography. Even small topographic features $(100 \mathrm{~m})$ sufficiently perturb the atmosphere promote precipitation. Relief on the order of 1 to $2 \mathrm{~km}$ can enhance precipitation by as much as $300 \%$ [6]. In addition to height, the amount of enhancement strongly depends on 
the orientation of the mountain slope relative to the oncoming wind direction, the speed of the wind, and the stability of the atmosphere.

The mid-latitudes atmosphere contains, on average, only about an inch of total precipitable water at any given time. Not all clouds precipitate, and those that do are not completely efficient at converting water vapor to precipitation. Generally only $20-30 \%$ of atmospheric precipitable water converts to precipitation during a storm. This observation begs the question: how do hydrologic extreme events occur, where storms precipitate inches to several inches over short periods of time? In order for precipitation totals to exceed fractions of an inch, there must be a mechanism in place that transports water vapor from a non-local source. Often times this non-local source is an ocean, but moisture can also be supplied from the continents in the form of evapotranspiration from plants, soil moisture or open bodies of water. In the Western US, the land surface 'recycling ratio' of moisture is low, meaning that precipitation starts as evaporation from far away locations.

The land surface records the signal of extreme precipitation events. A river flood occurs when the rate of surface runoff exceeds the river channel's capacity for routing water downstream. The river's bed and profile has adjusted, over geologic time and through erosive processes, to the regional hydroclimate and the normal distribution of runoff. Ignoring the possibility of rain-on-snow or post-fire/anthropogenic land use changes impacting runoff, it can be safely hypothesized that many floods must result from anomalous precipitation, and that anomalous precipitation can only come from either 1) an exceptionally efficient storm, or 2) the anomalous atmospheric transport of moisture into the region. Even a $100 \%$ efficient storm is limited by the roughly one 
inch of average precipitable water in the atmosphere. So in this simplified conceptual model we can intuit that anomalous moisture transport is a primary mechanism of flood generation. Thus, in many cases the flood, and the associated geomorphic response, begins life in the atmosphere as a pathway of enhanced moisture transport.

Research over the last three decades demonstrates conclusively that extreme hydrologic events and atmospheric water vapor transport are in fact fundamentally connected. 'Atmospheric Rivers' (henceforth, AR) first hypothesized and observed in the early 1990s, have been identified as one of the primary mechanisms of water vapor transport in the mid latitudes. They form in the warm sector of extratropical cyclones and transport warm, moist air from the tropics and subtropics towards the mid-latitudes at rates on the order to the world's largest terrestrial rivers. They are globally occurring and not particularly rare; at any given time, there are likely four or five present on the globe [17]. Numerous studies demonstrate the hydrological significance of AR. They are correlated with flooding [34], extreme winds [48], rain-on snow conditions [20], avalanches [24] and comprise significant if not the dominant sources of seasonal water supplies in many regions. In the California Sierra Nevada, as few as one or two AR events contribute between 30 - 40\% of total seasonal snow water equivalent (SWE) accumulation in the majority of years [18].

In June 2010, a major AR event caused widespread precipitation and flooding throughout central Idaho's Payette and Salmon river basins, leading to roadway failures and the potential for dam management failures. This event highlights some of the basic scientific questions of AR research and motivates this thesis. How well can we forecast the hydrologic responses from AR? Are there large scale weather 
features, climate indices or teleconnections associated with AR formation? Where do ARs cause significant precipitation, and what are the influencing factors? To what extent do AR control the hydroclimate, and the incidence of hydrologic extremes, in the intermountain Western US, specifically the SW central Idaho mountains? In this thesis, I consider the latter two questions. In the first chapter, I explore what factors impact the precipitation regime of AR events in mountainous SW central Idaho. In particular, I investigate snow-atmosphere interactions during SW central Idaho AR events. Acting through the surface energy balance, snow-atmosphere interactions are responsible for forcing climactic and weather phenomena across a range of spatial and temporal scales, examples of which I describe in detail later. Snowcover is highly variable across the intermountain West during the cool season when AR are active. The first section of chapter two reviews the literature of snow-atmosphere interactions and describes key components of the snow energy balance. The second section of chapter two presents the results of AR snow-sensitivity experiments using a high resolution numerical weather prediction model for a March 1998 AR event.

In the appendix, I review some of the recent AR literature, and in particular focus on the hydrologic significance of AR events in the Western US. I present results from an AR detection code that I developed to identify AR events that enter the SW central Idaho mountains over the past 30 years from climate reanalysis data. 


\section{CHAPTER 2}

\section{ROLE OF SNOW-ATMOSPHERE INTERACTIONS IN CENTRAL IDAHO ATMOSPHERIC RIVER EVENTS}

The goal of this chapter is to quantify the role of snowcover forcing in the atmospheric system during periods of AR activity. This is the first modeling study, to our

knowledge, that addresses this question. Snow modifies the fluxes of energy, in the form of radiative and turbulent energy exchanges, between the land surface and atmosphere. In the first section, I review snow-atmosphere interaction literature. I present the results of a series of numerical modeling experiments of snow-atmosphere interactions during a central Idaho landfalling AR event from March 1998. This study uses the Advanced Research (ARW) version of the Weather Research and Forecasting (WRF-ARW) high resolution, convection permitting model coupled with the Noah-MP land surface model, through which we may query the complex interactions between the atmosphere and land surface.

\subsection{Literature Review of Snow Atmosphere Interactions}

Earth's weather and climate are driven by energy from the sun. Equatorial regions receive higher amounts of solar radiation, and global circulations redistribute 
energy between the latitudes in the form of weather. The latitudinal energy imbalance combined with the tilt of Earth's rotational axis are the first order drivers of global climate. The second order driver of Earth's weather and climate is surface heterogeneity [44]. On average, approximately half of the solar energy entering the atmosphere does so from the land surface in the form of thermal radiation ('longwave'), latent heat associated with energy absorbed/released during the phase transitions of water, and sensible heat exchange associated with the diffusion of energy between bodies in contact of different temperatures [44]. Consequently the thermal, radiative and surface roughness properties of land surface materials, and regions of large heterogeneity of these surface properties, force the behavior of the weather and climate. For example, small temperature perturbations in the ocean system, such as the El-Nino-Southern-Oscillation, are major seasonal influences on climate and are among the primary mechanisms of seasonal climate predictability in the mid-latitudes. Mountains influence patterns of precipitation (as described in Chapter 1) as well as global atmospheric circulation.

The regions of the Earth covered by snow and ice impact weather and climate. Snow and ice each has a high reflectance in the shortwave spectrum ('albedo'). Snow and ice reflects more solar radiation relative to non-snow or ice covered surfaces, promoting cooling at the surface, and thus the persistence and growth of snow and ice. Once snowmelt begins, another positive feedback mechanism takes place. Snow crystals metamorphose and grow in size, decreasing albedo, which promotes further melt. The positive Snow-Albedo-Feedback (SAF) mechanism has contributed to the complete freezing of the oceans during 'snowball-Earth' periods. During the 
Last Glacial Maximum, the SAF promoted favorable climactic conditions for the persistence of continental glaciers throughout North America, Europe and Asia. There are many knowledge gaps and deficiencies in the scientific understanding of seasonal snow's role as a forcing of weather and climate. The cryosphere includes both permanent (ice caps, glaciers) and seasonal snow and ice. As agents of climactic forcing, Earth's regions of persistent snow and ice have received more research attention than seasonal snowpacks. During winter, seasonal snow covers a mean average maximum extent of 47 million $\mathrm{km}^{2}$, over $98 \%$ of of which occurs in the Northern Hemisphere [2]. However, the spatial and temporal variability of snowcover in the Northern mid-latitudes is large. A single weather event can increase or decrease snowcover extent within a basin by $100-1000 \mathrm{~s}$ of $\mathrm{km}^{2}$ and there can be large annual and inter-annual variation in snow-covered-area (SCA) and snow-water-equivalent (SWE) [10]. Historically, efforts to understand snow-atmosphere interactions have been limited by poor representation of snow processes in atmospheric models, spatial resolution of atmospheric models, and data availability.

\subsubsection{Unique Physical Properties of Snow}

Snow has many unique properties that control the fluxes of energy, mass and momentum between the land surface and atmosphere. Snow is one of nature's best insulators with a low thermal conductivity that strongly depends on its density, metamorphic state, and physical structure. The consequences are two fold: the atmosphere is insulated from ground heat flux, and the ground is insulated from the atmosphere. Snow has a high thermal emissivity. Emmissivity is defined as the 
ratio of radiant energy flux between a grey body and that of a perfect blackbody. Fresh snow has an emissivity of .85-.99, very close to that of a perfect blackbody. By Kirchoff's law, absorptivity is equal to emissivity. Consequently, snow absorbs nearly all incident longwave radiation and re-emitts close to the maximum amount allowed by the Stefan Boltzmann law (proportional to the 4th power of its temperature). While snow has a low reflectance in the longwave spectrum, it has a high reflectance in the shortwave portion of the visible spectrum (albedo). The albedo for fresh snow is typically between .85 and .95 . As snow ages, typically the albedo decreases, from either snow metamorphism, snow-melt, or the deposition of dust and aerosols. Snow

has a high latent heat of fusion $\left(3.34 \times 10^{5} \mathrm{Jkg}^{1}\right)$, and thus requires large amounts of energy to melt. Consequently, conditions in which air temperatures are greater than $0^{\circ} \mathrm{C}$ promote sensible heat exchange directed toward snow surfaces, and melting snowpacks in particular act as large energy sink. As an atmospheric forcing, there are two important criteria for assessing the effect of seasonal snow: snow covered area and snow 'cold-content', defined as the amount of energy required to completely melt a snowpack. Even thin snow packs, with low cold-contents, still have a high albedo and contribute to the SAF mechanism.

\subsubsection{Examples of Snow-Atmosphere Interactions}

A variety of observational, statistical, and modeling based studies address snow's role in the atmosphere system. Over a century ago, British meteorologists speculated that the Indian Monsoon precipitation was anti-correlated with the previous Spring's Himalayan snow cover [7]. Subsequently, multiple studies demonstrated 
an anti-correlation between Eurasian (though not exclusively Himalayan snowcover) and July-August Indian monsoonal precipitation [23] [4]. The positive Eurasian snow anomaly acts as an energy sink, inhibiting land surface and lower atmospheric heating, resulting in cold spring temperatures and reduction of the summer thermal low. Consequently, the ocean-land temperature and pressure gradients necessary for Monsoonal system formation weaken and reduce total precipitation [5]. A similar effect may occur in the North American Monsoonal system, which occurs in July and August across the American Southwest and North central Mexico [22]. However, the relationship is much less conclusive than for that of the India Monsoon - Eurasian Snow connection.

Given the large size of the Eurasian continent and the variability of snowcover across it, research has explored it's potential role as a forcing of global climate variability and predictability. Cohen et al (2001) demonstrated that October Eurasian snowcover is correlated with the strength of the 'Siberian High', a semipermanent synoptic ridge of high pressure that occurs during winter months [11]. Currently, a statistical sub-seasonal weather prediction models uses October Eurasian snowcover as a predictor for North American Winter weather through a linkage with the phase of the Arctic Oscillation [8] [9]. Xu et al (2011) assessed the coupling strength between snowcover and meteorological variables using a global climate model [52]. In keeping with other studies, the authors find that the strongest coupling strength generally occurs during Spring and early Summer months when solar insolation is at the highest; during these times the SAF effect is the strongest. The authors find that the second mechanism of snow-atmosphere interaction manifests in the snow-soil 
moisture relationship. Spring snow anomalies are associated with Spring and Summer soil moisture anomalies, which trigger soil-precipitation feedbacks particularly in regions of strong summertime convective activity. The results demonstrate that the there exists a coupling between snowcover and precipitation, in addition to a stronger coupling between snow cover and 2 meter air temperature. The authors do not posit or explore what physical mechanism explains the coupling.

A variety of studies have attempted to quantify snow cover's role in depressing air temperatures at the surface and lower troposphere. Observational studies of snow and air temperature relationships are difficult to interpret, given the circular relationship: is a negative air temperature anomaly driven by snow, or does the negative air temperature anomaly predict the existence of snow? Nonetheless, many studies have employed statistical approaches to do just this. Walsh et al (1982) examined surface temperature departures resulting from snow cover as the change from expected temperature given the $700 \mathrm{hPa}$ height temperature, a height above the surface that is assumed to be above the planetary boundary layer and independent of effects of the land surface. Their results suggest that snowcover accounts for as much as $10-20 \%$ of the variance in monthly winters temperatures in regions on the edge of snow-zones in the United States, and that the effects are greatest in the late winter [50]. Mote (2007) used an analysis of variance approach to demonstrate that surface temperatures can be reduced by as much $4.6^{\circ} \mathrm{C}$ during the daytime in grass covered, open sites in the United States [31]. Baker et al (1992) examined surface temperature and radiation components across 11 years at a Minnesota site, and found that the dominant temperature depressing mechanism was higher snow 
albedo increasing outgoing shortwave radiation. They conclude that snow cover greater than $10 \mathrm{~cm}$ decreased $2 \mathrm{~m}$ air temperature by more than $8.4^{\circ} \mathrm{C}$, while $2 \mathrm{~cm}$ snowcover decreased $2 \mathrm{~m}$ air temperature by $6.4^{\circ} \mathrm{C}$ on average [3]. Using a snowpack mass balance and energy model, Ellis and Leathers (1999) found that maximum $2 \mathrm{~m}$ air temperatures without snow present increased by $10-15^{\circ} \mathrm{C}$ and minimum temperatures increased $1-2^{\circ} \mathrm{C}$. They, however, found little difference between deep snowcover and lesser snowcover [15]. Walsh and Ross (1988) explored snowcover impacts on lower atmosphere air temperatures using a model-based approach with NCAR's Community Forecast Model, and found that greater prescribed snow covered area reduced surface temperatures by as much as $5-10^{\circ} \mathrm{C}$ for 30 day forecasts [49].

Surface cooling from snow impacts the stability of the atmosphere. An atmospheric temperature profile with an ambient lapse rate greater than the adiabatic lapse rate is stable, and resists the ascent of air parcels. 'Inversions' are exceptionally stable conditions where environmental temperature increases with height. Snow cover very effectively radiates longwave radiation, thus promoting surface cooling. Snowcover, and clear skies in which longwave radiation exits into space, are often predictive of inversions (Prof. Cliff Mass, personal communication).

Recent modeling efforts have characterized snow atmosphere interactions on regional and local scales. Letcher and Minder (2017) use the WRF regional climate model to quantify SAF in the Colorado Rockies under current and 'pseudo-global warming' scenarios. They demonstrate that the cooling effect over snow covered grid cells, driven by reductions in net shortwave radiation, are balanced by increases in the horizontal energy transport driven by atmospheric motions. Effectively, atmospheric 
motions dampen the cooling response associated with snowcover. In this way, the SAF mechanism has non-local implications over even non-snow covered regions [27]. The same authors also evaluate the SAF impact on diurnal mountain wind systems. Diurnal wind systems are prevalent in regions of mountainous terrain, where differential heating between low and high elevations establish pressure gradient forces that typically drive diurnal upslope and downslope winds. The authors found that numerical models well simulated diurnal patterns of mountain winds in the Colorado headwaters regions, and that the snow-albedo feedback mechanism increases the strength of daytime upslope winds and decreases strength of nighttime downslope winds during non-stormy periods. Using a large-eddy-simulation, Mott et al (2015) simulated boundary layer processes for regions patchy snow cover over a small (200m) alpine catchment during both quiet and windy conditions [32]. They used a large eddy simulation with a $5 \mathrm{~m}$ horizontal and $.5 \mathrm{~m}$ vertical spatial resolution and an integration time of 700s. Their results demonstrate that thermal differences between snow covered and snow free regions create buoyancy driven winds (katabatic winds) which they found drive rates of turbulent heat fluxes over snowcovered regions. Moreover, turbulent kinetic energy above the snow-surfaces are suppressed.

\subsubsection{Synopsis of Literature}

Seasonal snow is among the most variable land-surface components in the Northern Hemisphere, both spatially and temporally. Due to the high albedo, low thermal conductivity, high emissivity, and high latent heat of melting, the results from a variety of modeling and observational studies demonstrate that snow forces the 
atmosphere across a wide range of spatial and temporal scales, from the $1000 \mathrm{~s}$ of kilometers across an entire season, to the 10s of meters on the order minutes and hours. The SAF mechanism is generally understood as the dominant mode of snow forcing in the atmosphere system, especially during Northern Hemisphere Spring. During the geologic past, there are have been several times in which the SAF mechanism led to the formation of extensive continental glaciers, likely in addition to a 'Snowball-Earth' scenario. Eurasian snowcover is highly correlated with monsoon systems and the variability of Northern Hemisphere winter circulation, and a similar mechanism may operate in the American Southwest monsoon system. Snow depresses surface air temperatures and promotes atmospheric stability, including the likelihood of temperature inversions. Regional climate modeling studies demonstrate that snow has non-local, regional influences on weather and climate over even non-snowcovered regions. While snow's influence on the climate system is well documented and researched, snow-atmosphere interactions are poorly understood on short time scales (hours to weeks) and regional scales [52]. Advances in coupled land-atmosphere models and the computational feasibility of convection permitting model resolutions mean that the the atmosphere's dynamic response to snow forcing can now be interrogated. 


\subsection{AR-Snow Sensitivity Experiments}

\subsubsection{Introduction}

There has been little effort to understand how the land surface snow cover states prior to and during the arrival of ARs, acting on the surface mass and energy balance, impact the onset, extent, and evolution of precipitation accumulation during AR events. Does snow forcing influence orographic precipitation enhancement, and does the precipitation fall as rain or snow? In this section I test these questions using a high resolution numerical weather prediction model in a central Idaho study domain.

\subsubsection{Methods}

\section{WRF Model Description}

I used the advanced research version of the Weather Research and Forecasting model (WRF-ARW, referred to as WRF hereafter) [45] to simulate a March 1998 Atmospheric river event that impacted the Idaho mountains. The WRF model is a community developed, fully-coupled numerical weather prediction model used for both for research and operational forecasting. Global weather and climate model products operate at a coarse (1 - .5 degree grid cells, typically) spatial resolution and do not capture the complex interactions of atmospheric motions, land surface processes and topography that profoundly effect temperature and precipitation in mountainous mid-latitude regions [39] [26]. WRF can be configured as a dynamical downscaling model, where a reanalysis product or climate projection prescribes the lateral and initial boundary conditions for the model equations of motion. The 

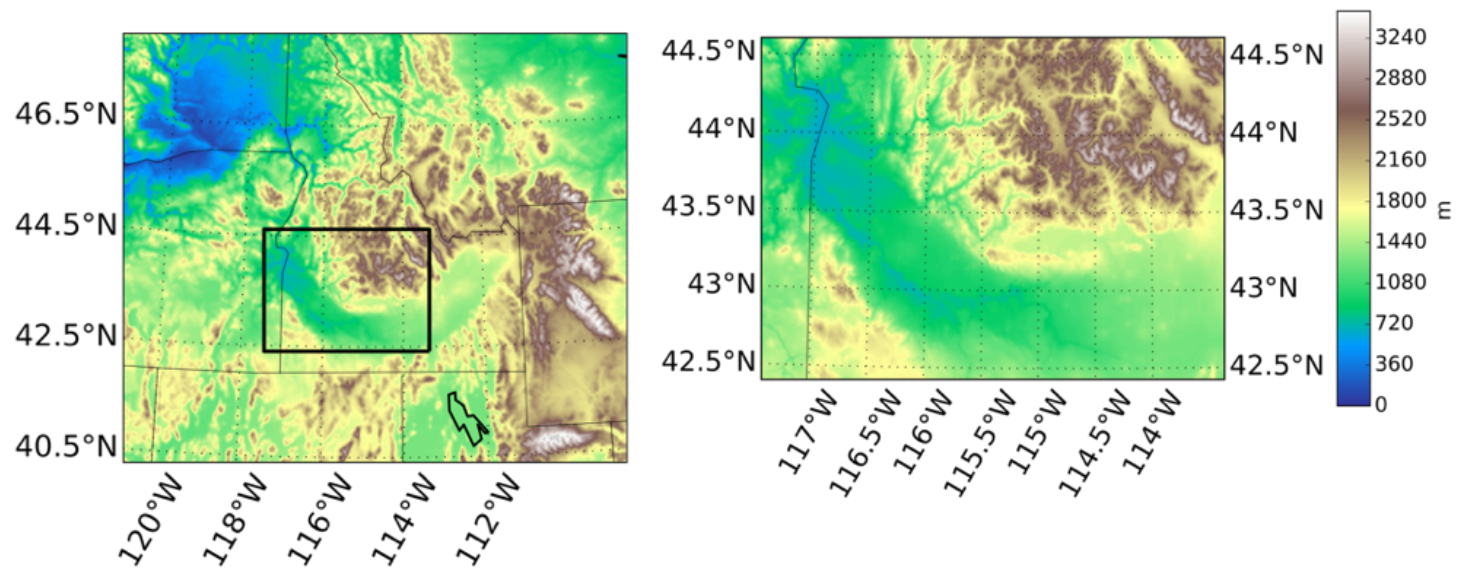

Figure 2.1: WRF Model Domains. The outer domain has a $3 \mathrm{~km}$ spatial cell resolution, and the inner cell has a $1 \mathrm{~km}$ resolution

WRF grid uses a finer mesh with higher resolution topography than the reanalysis product. In this way, the interactions between the atmosphere and the topography can be resolved with increased fidelity. In this configuration, WRF has repeatedly demonstrated excellent performance at forecasting/hindcasting precipitation and snow accumulation in a variety of locales, and rivals the skill of interpolated, station based precipitation products in mountainous regions [39] [13].

We use two nested domains with different resolutions: an outer grid with a $3 \mathrm{~km}$ spatial resolution that encompasses a large region of the Snake River Basin, and an inner, $1 \mathrm{~km}$ spatial resolution domain encompassing the Boise, Payette and Salmon river basins (Figure 2.1). For this research, we use the Climate Forecast System Reanalysis (CFSR) to provide lateral and intial boundary conditions to the WRF model that encompass the AR event in question. CFSR is a state of the art, global, coupled land-atmosphere-ocean reanalysis product. The CFSR system uses 


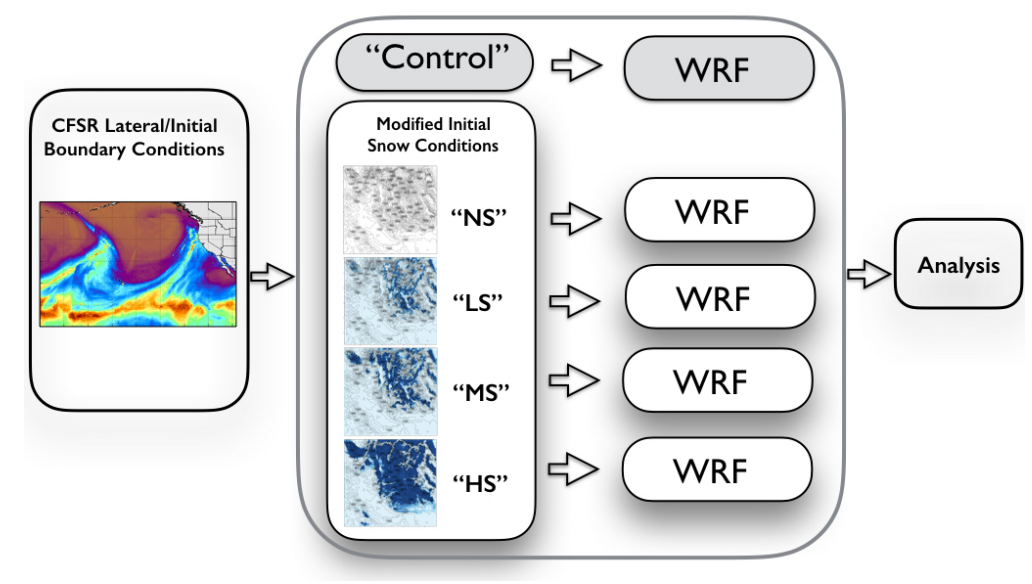

Figure 2.2: Experimental Design. For the 1998 AR event, 5 total experiments are performed: 'No-Snow', 'Low-Snow', 'Medium-Snow', 'High-Snow' initial conditions, as well as a control run with unmodified initial conditions.

advanced data-assimilation schemes to provide high-resolution global best estimates of atmospheric states at 6 hourly intervals. CFSR is available freely at 0.5 degree resolution from the NCAR Research Data Archive. Model 'nests' are typically used in mesoscale numerical models for numerical reasons: the boundary conditions for the innermost $1 \mathrm{~km}$ domain are driven by the encompassing $3 \mathrm{~km}$ domain, which are driven by the .5 degree CFSR boundary conditions. Our model set-up uses 50 vertical eta levels. Eta coordinates are a hybrid terrain-following coordinate system. For numerical stability purposes it is more advantageous to represent grid cells on eta levels as opposed to pressure or elevation surfaces.

WRF has many physical parameterization options designed for different model configurations and research goals. We employ a convection permitting model configuration, meaning that the processes of convection are explicitly resolved by the equations of motion, as opposed to convective parameterizations that make gross 


\begin{tabular}{|c|c|}
\hline Physics Parameterization & Option \\
\hline Planetary Boundary Layer & Mellor-Yamada-Janjic (Eta) TKE \\
\hline Microphysics & Thompson [47] \\
\hline Radiation & Community Atmosphere Model (CAM) [12] \\
\hline Land Surface & Noah MP [36] \\
\hline Surface Layer & Monin-Obukhov similarity theory \\
\hline
\end{tabular}

Figure 2.3: WRF Parameterization options used for this research.

assumptions about updraft velocities. WRF also uses parameterizations to account for the formation and precipitation of hydrometeors (Microphysics), sub-grid-scale flux of energy and mass into the atmospheric column from the surface, friction velocities and exchange coefficients for the calculation of heat terms by the land surface model and Planetary Boundary Layer (PBL) model, atmospheric heating due to both solar (shortwave) and terrestrial (longwave) radiation, and a land surface model to provide heat and mass fluxes at the bottom boundary of the atmospheric column. Our model configuration uses the Monin-Obukhov similarity theory surface layer scheme, the Community Atmosphere Model (CAM) short and longwave raditaion schemes, the Mellor-Yamada-Janjic (Eta) TKE planetary boundary layer scheme, Thompson microphysics and the Noah MP land surface model. For a more complete description of each physics option, refer to Skamrock et al (2005) [45].

The land surface model in WRF supplies fluxes of moisture and energy to both the surface layer scheme and the PBL scheme, the later of which is responsible for the vertical transport into the entire atmospheric column. The Noah MP land surface model (LSM) uses a three layer snow model that accounts for melt/refreeze/liquid water storage capability, in addition to a separate model layer for vegetation with subgrid parameterizations for canopy processes [36]. In this configuration, Noah-MP 
is set to ingest the hydrometeor phase (snow, rain, graupel) from the microphysics scheme in addition to rate and total amounts of precipitation. Noah MP models emissivity and albedo for each grid point, parameters which are used by the surface layer scheme to model reflected shortwave and upwelling longwave radiation budgets. Sub-grid snow-cover fraction (between 0 and 1.0) is a diagnostic value calculated in Noah-MP based on empirically derived SWE/SCA relationships. Noah MP represents a marked improvement over Noah in modeling snow processes, though notable biases persist [51]. Our configuration of Noah-MP uses a simple snow albedo model where snow surface albedo decays with age. For a complete description of Noah-MP, consult Nui et al (2011) [36].

\section{Experimental Setup}

For the March 1998 AR event, I perform a total of 6 simulations. First, I ran one 'control' simulation with the standard CFSR surface and snowpack state for this time period. Then, five 'SNOWMOD' scenarios are created, where I prescribe, by direct insertion, the initial land surface snow covered area, snow depth, snow skin temperature and density into the model initial condition file (the 'wrfinput' file). The maps presented in Figure 2.5 show the snow-covered area state for each of these model scenarios. This yields a total of six ensemble members: five modified initial conditions (SNOWMOD) and the one standard (control) simulation (Figure 2.2). The lateral boundary conditions are the same for the control and 'SNOWMOD' experiments. In this way, the effects of snow cover alone, as opposed to atmospheric forcing, can be isolated an tested. Model runs are initialized approximately two days 

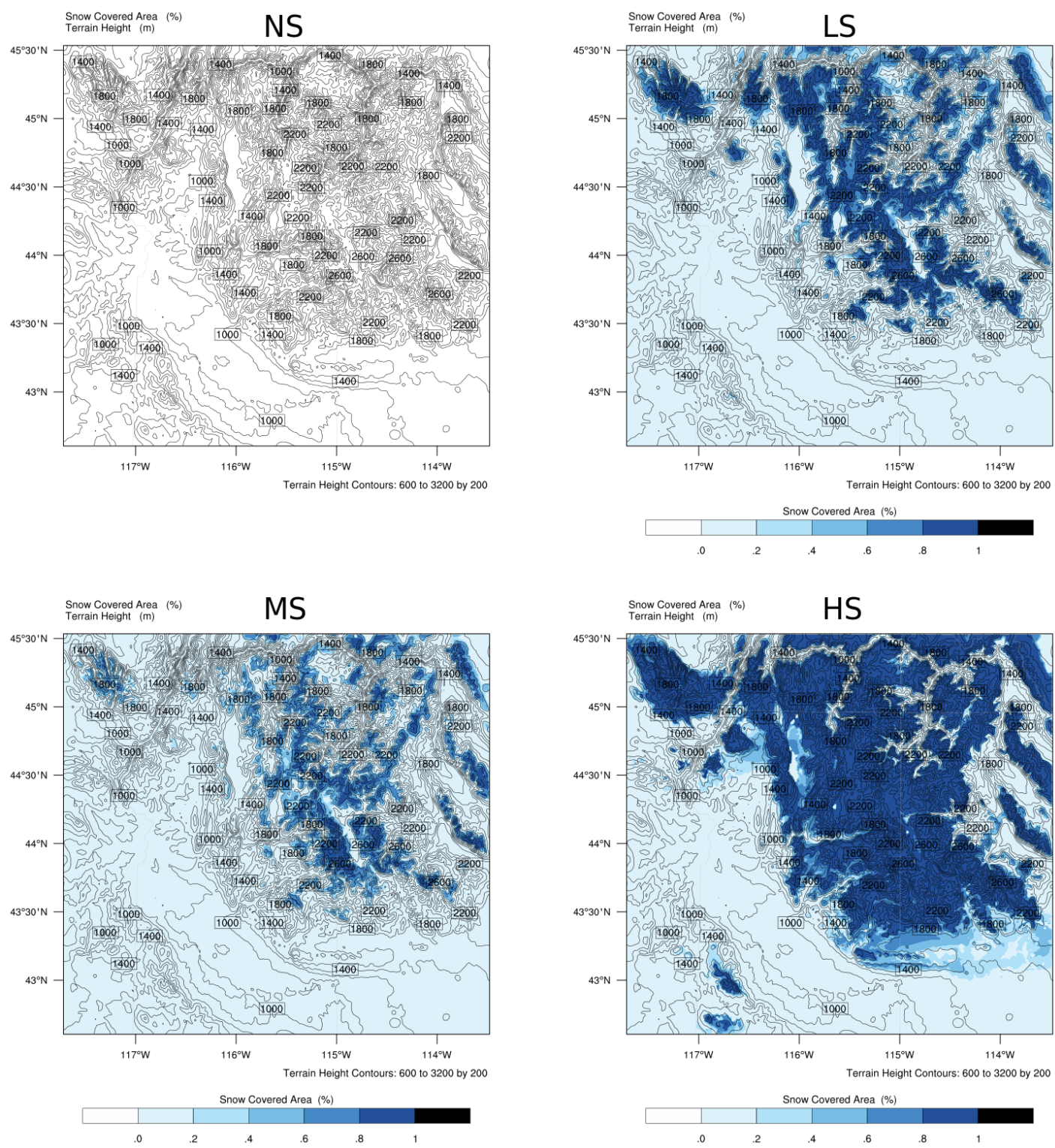

Figure 2.4: Initial Snow Covered Fraction maps. Clockwise from top left: No Snow (NS), Medium Snow (MS), Low Snow (LS), High Snow (HS) 


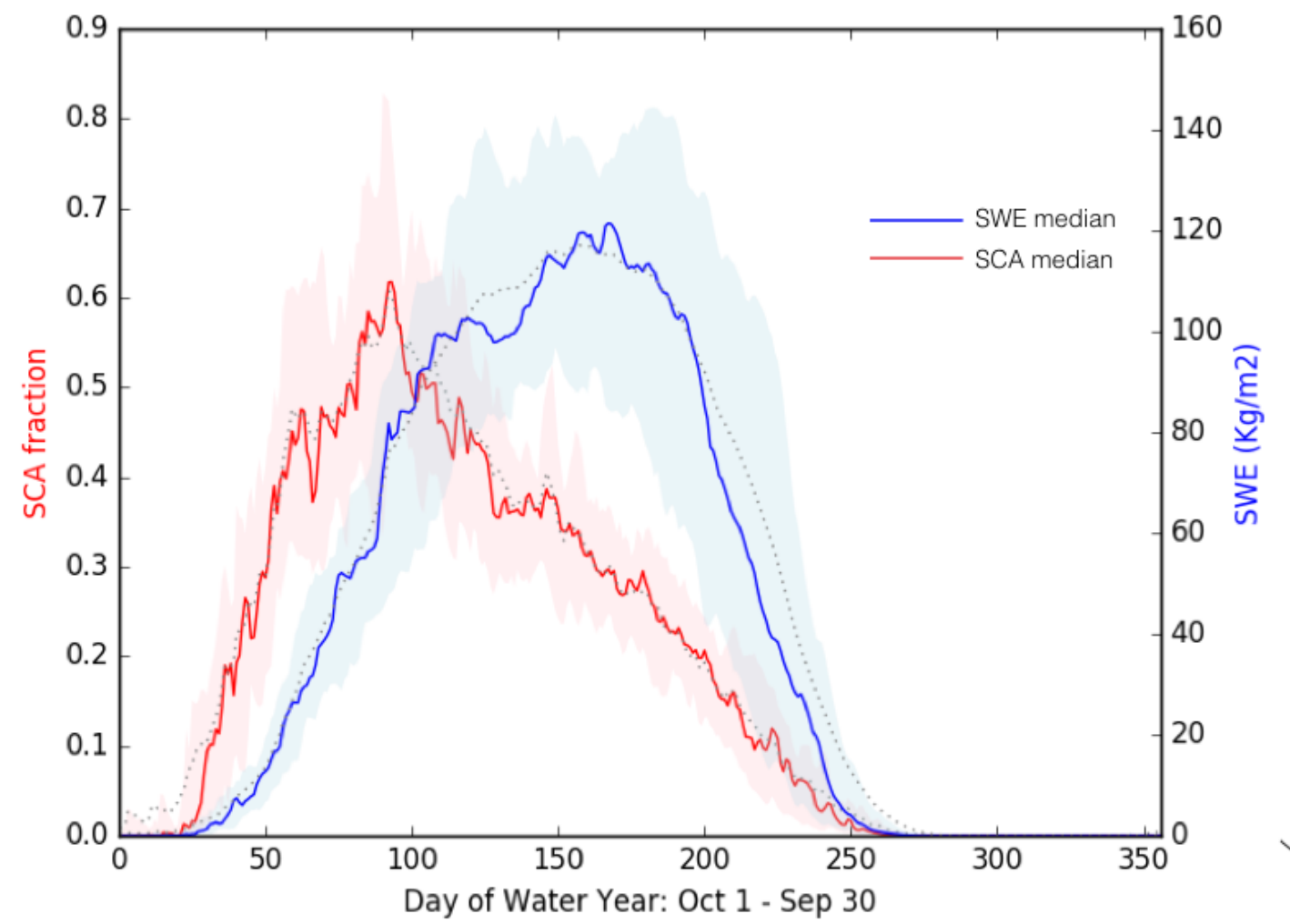

Figure 2.5: Distribution of mean domain wide Snow Water Equivalent (blue) and Snow Covered Area (red) by day-of-water year between 1986 and 2016. The solid lines are the median, dotted lines the mean, and shaded regions are the interquartile range 
prior to the onset of each precipitation event, allowing for adequate model spin up of the atmosphere.

The high resolution snow data used in the SNOWMOD cases are copied from a 30 year WRF climate dataset from the same region, run with the same model configurations and spatial resolutions [16]. The snow conditions have been selected to sample the range of possible snow conditions. Figure 2.5 shows the distributions from the 30 year WRF dataset of domain average snow water equivalent and snow covered area by day of water year from which the snow states were sampled.

During the control scenario for the March 1998 event, there is sparse snowcover primarily in the higher elevation regions, and is most similar to the "LS" case. During the HS case, there is a large coverage of low elevation snowpack. For this region of the intermountain West, it is typical to have persistent snow during the winters in mountainous, higher elevation regions, and infrequent low elevation snow coverage across the Snake River plain. The HS case is snow condition of maximum snow coverage across across the 30 year WRF dataset (Figure 2.5). The snow skin temperatures (not shown) for all SNOWMOD members are near $0^{\circ}$ Cinitially.

\section{Energy Budget Analysis}

$$
\frac{d E}{d t}=F_{T O A}+F_{S F C}-\nabla \cdot \mathbf{f}
$$

To analyze the effects of variable initial snow conditions in the atmospheric system, we analyze the terms of tropospheric energy budget illustrated in Figure 2.6. This method has been employed in several other WRF regional climate studies [27][37]. The energy storage, $E$, of a column of the atmosphere is the sum of it's sensible, 


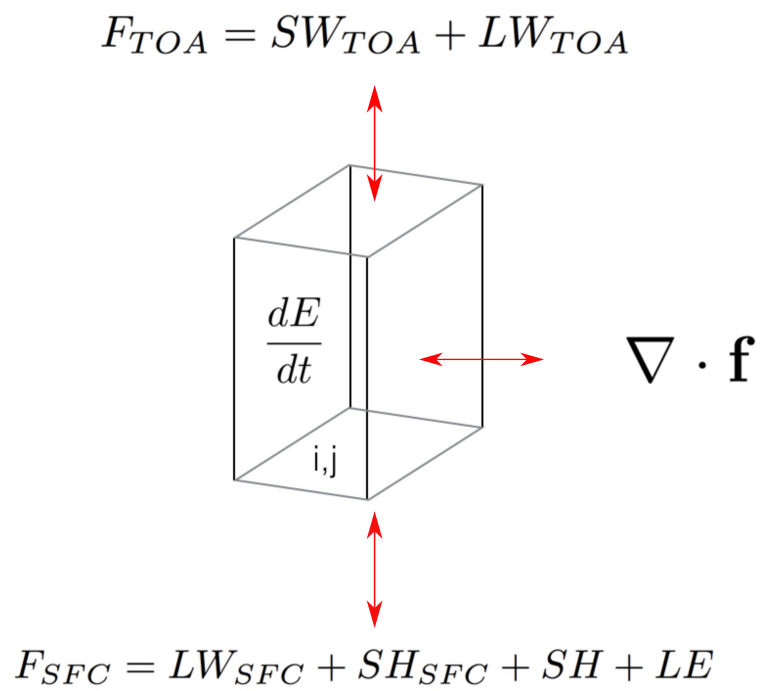

Figure 2.6: The components of the atmospheric energy budget. Refer to text for descriptions of terms.

latent, kinetic, and potential energy. The energy tendency, $\frac{d E}{d t}$, must balance the the energy flux at the top of atmospheric column $\left(F_{T O A}\right)$, the net energy flux from the land surface $\left(F_{S F C}\right)$, and the divergence of horizontal energy transport between columns $(\nabla \cdot \mathbf{f})$. The energy tendency is calculated as the difference between the beginning and end timesteps of the model, divided by the change in time in seconds, yielding an average flux in terms of watts per meters squared. The terms of Equation 2.1 can be expanded:

$$
\begin{gathered}
E=\frac{1}{g} \int_{P, t o p}^{P, s f c}\left(c_{p} T+L_{v} Q+\Phi+k\right) d p \\
F_{S F C}=L W_{S F C}+S W_{S F C}+S H+L E
\end{gathered}
$$




$$
\begin{gathered}
F_{T O A}=S W_{T O A}+L W_{T O A} \\
\mathbf{f}=\frac{1}{g} \int_{P, \text { top }}^{P, s f c}\left(c_{p} T+L_{v} Q+\Phi+k\right) \mathbf{V} d p
\end{gathered}
$$

Equation 2.2 models the total energy storage within the atmospheric column, integrated from the surface $(P, s f c)$ to the top-of-atmosphere $(P, t o p)$. $\mathrm{P}$ is pressure in pascals, $L_{v}$ is the latent heat of evaporation, $\mathrm{Q}$ is the specific humidity, $C_{p}$ is the specific heat capacity of dry air at a constant pressure, $\mathrm{T}$ is temperature in Kelvin, and $\Phi$ is the geopotential energy. The moist static energy is the sum of the terms $C_{p} T$, $\Phi, L_{v} Q$, and is comparatively much greater in magnitude than the kinetic energy, $\mathrm{k}$. For this reason kinetic energy has been omitted from this calculation. In this energy budget formulation, positive signs indicate a flux of energy into the atmospheric column and negative sign indicates energy leaving the column. The surface energy budget, $F_{S F C}$ is calculated from Equation 2.3, where SH and LH are surface sensible and latent heat fluxes respectively. If the sum of Equation 2.3 is positive, there is a net flux of energy from the land surface into the atmospheric column. The top of atmosphere energy balance (Equation 2.4) is the sum of long and shortwave radiation. The sign of the longwave TOA term will typically be negative, since the thermal radiation emitted upwards from clouds and the land surface is much greater than the small amount of longwave received from the upper stratosphere. Shortwave radiation $\left(S W_{T O A}\right)$ is the difference between incoming solar radiation and the outgoing solar radiation reflected by clouds or the land surface. In Equation 2.5, 
$\mathbf{V}$ is the horizontal wind vector. By definition, a negative $\nabla \cdot \mathbf{f}$ indicates a source of energy to the column. Given that in WRF the momentum equations are energy and mass conserving, $\nabla \cdot \mathbf{f}$ can be approximated by differencing the remaining terms of Equation 2.1 [27]. Since the energy tendency is calculated between the beginning and end model timesteps, each term calculated from Equation 2.1 is the average flux over the model time period.

\section{Atmospheric Stability Analysis}

As an air parcel lifts over a mountain range, it cools adiabatically, and, if the cooling is sufficient to lower the saturation vapor pressure to below that of the partial pressure of vapor within the parcel, the parcel becomes saturated, and clouds form in the presence of sufficient cloud-condensing nuclei. If the precipitation forming processes within the cloud are sufficient, hydrometeors grow and precipitate. At the same time, as the parcel is pushed across a mountain barrier in a stably stratified atmosphere, buoyant forces resist the ascent, given that the air mass will be denser than the surrounding air. In order for the air mass to cross and ascend the mountain barrier, the kinetic energy of the parcel must be greater than the buoyant restoring forces that the air mass encounters during lifting. Roe (2005) provides a review of the

dynamics of precipitation in mountainous regions [40]. Precipitation enhancement also depends on the direction of incoming flow relative to the mountain barrier, the incoming flow speed and the total height of the mountain barrier.

The Froude number is a useful parameter for characterizing orographic precipitation enhancement [25] [6]. For continuously stratified, nonrotating, inviscid flow 
over a $2 \mathrm{~d}$ obstacle of height $h$, the Froude number is given by $F=\frac{U}{N h}$, where $U$ is the incoming windspeed $(\mathrm{m} / \mathrm{s})$ and $N$ is the Brunt-Vaisalla (BV) Frequency. The Brunt-Vaisalla frequency is a measurement of atmospheric static stability defined by $N=\left(\frac{g}{\theta_{v a}} \frac{\partial \theta_{v a}}{\partial z}\right)^{\frac{1}{2}}$, where $\theta$ is the virtual potential temperature, $z$ is height, and $g$ is gravitational acceleration. A higher BV frequency indicates a more stable atmosphere, i.e, one that is more resistant to the ascent of an air parcel. Low froude number cases (approximately less than 1) may be indicative of blocked airflow, where the incoming air mass is inhibited from crossing the mountain barrier, and precipitation enhancement occurs further upwind of the mountain range. Using a NWP model, Hughes et al (2009) show that the Froude number is closely related to precipitation rates and slope heights on California's coast range [25]. Lueng et al (2009) speculate that small changes in low level stability, and Froude number, relate to the distribution of orographic precipitation during Western US AR events [28]. Conceivably, cooling associated with snow cover may increase static stability, modifying the low level flow around terrain and thus changing the orographic precipitation regime. We test how snowcover impacts stability of the lower troposphere during periods of AR activity. Since the assumption of two-dimensional flow is not valid in the complex topography of central Idaho, I do not calculate the Froude number explicitly, only the BV frequency. Following Hughes et. al 2009, I calculate the BV frequency for the lower 5 model surface levels and compare amongst SNOWMOD model scenarios. 


\begin{tabular}{|l|lll|}
\hline & Rain & Snow & Unit \\
\hline Control & $\mathbf{5 6 0 . 2 9}$ & $\mathbf{1 8 4 5 . 2 3}$ & $\mathbf{m}$ \\
\hline NS & 99.28 & 98.29 & $\%$ \\
LS & 99.57 & 101.42 & $\%$ \\
MS & 98.50 & 98.10 & $\%$ \\
HS & 98.16 & 96.99 & $\%$ \\
\hline
\end{tabular}

Table 2.1: Accumulated Precipitation summed across the entirety of domain 2 for the control run (meters) and \% of the control precipitation for SNOWMOD scenarios

\subsubsection{Results}

The results of the SNOWMOD experiments for the 1998 AR are presented in the following section. Three primary observations are compared: changes in total accumulated precipitation, atmospheric energy budget terms, and atmospheric stability between SNOWMOD endmembers.

Overall, during the 8-day period between March 19-27, 1998, WRF domain 2 (Figure 2.1) received an average of $16 \mathrm{~mm}$ of total liquid equivalent precipitation, and the domain wide maximum was $116 \mathrm{~mm}$ (approximately four inches), of which approximately one quarter on average fell in the frozen phase (snow or graupel). Table 2.1 shows the accumulated precipitation summed across the entire domain for the control run and the corresponding percentage of the control run precipitation for each SNOWMOD experiment.

Figures 2.7 and 2.8 show the total accumulated precipitation differenced between SNOWMOD members and the control run. During the March 1998 AR, the precipitation differences SNOWMOD experiments and the control differ by $+/-10 \mathrm{~mm}$ of liquid equivalent of frozen precipitation. The anomalies are on the order of $+/-$ $5 \mathrm{~mm}$ of liquid water. For the March 1998 AR, where there was little initial snow 

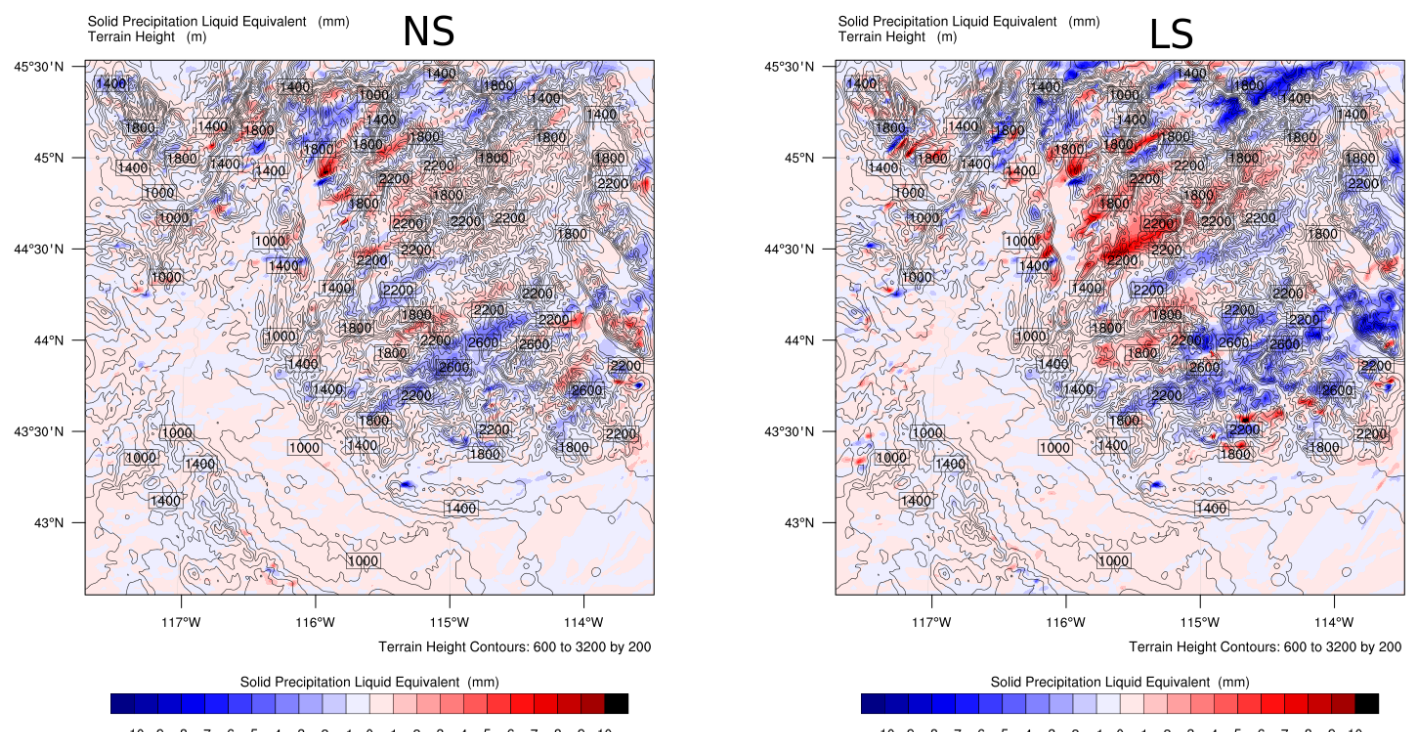

$\begin{array}{llllllllllllllllllllll}-10 & -9 & -8 & -7 & -6 & -5 & -4 & -3 & -2 & -1 & 0 & 1 & 2 & 3 & 4 & 5 & 6 & 7 & 8 & 9 & 10\end{array}$

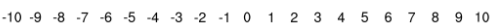
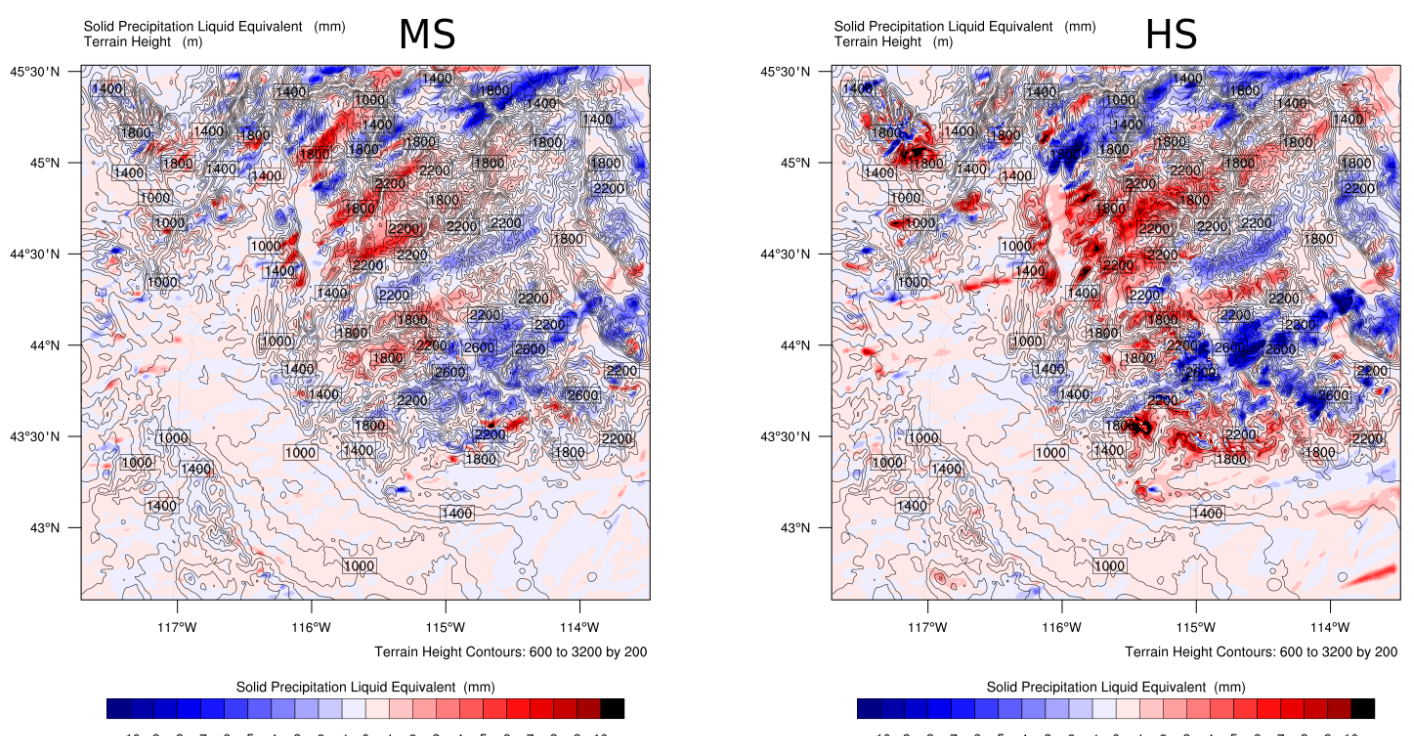

Figure 2.7: Difference in total accumulated snow and graupel (liquid equivalent) between SNOWMOD scenarios (clockwise from top left) NS, LS, HS, MS and control run 

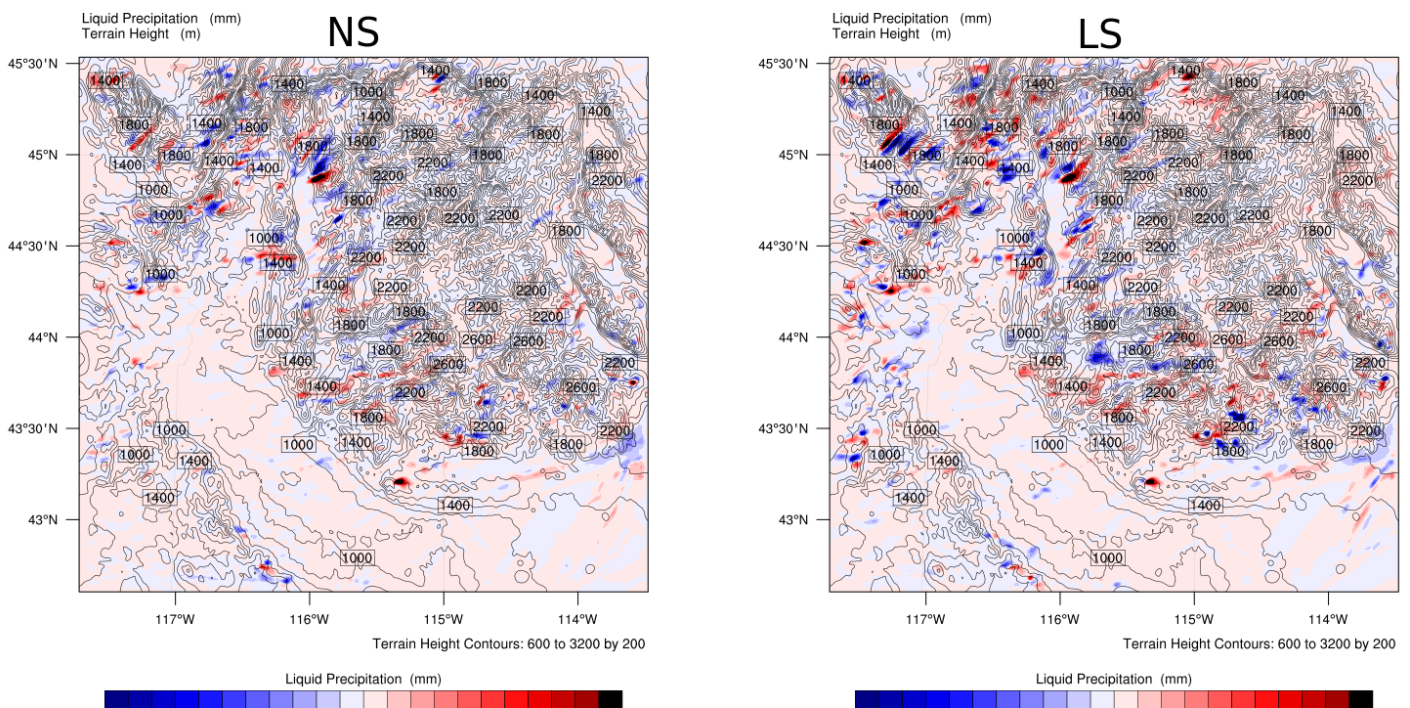

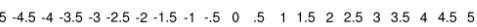

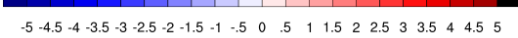
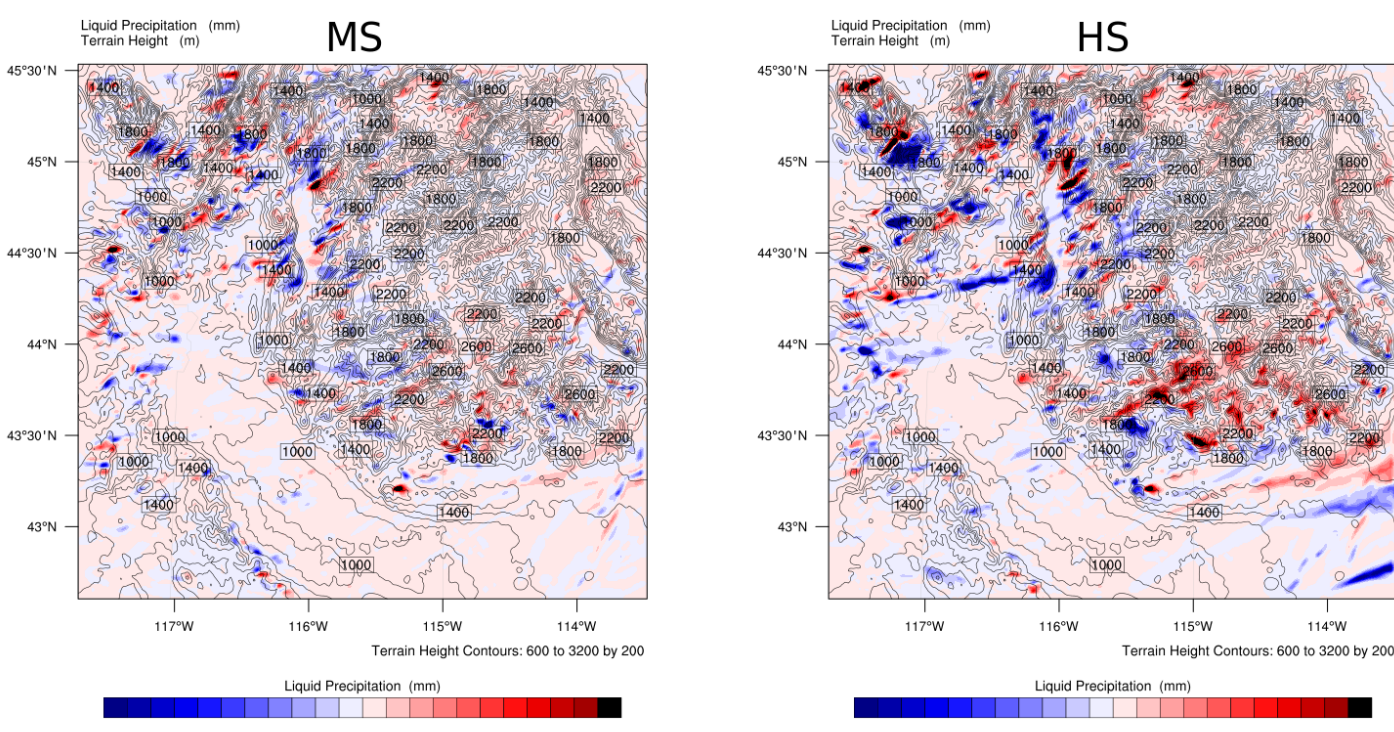

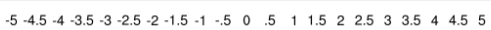

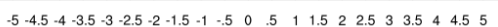

Figure 2.8: Difference in total accumulated rain between SNOWMOD scenarios (clockwise from top left) NS, LS, HS, MS and control run 
cover during the 'Control' case, the greatest differences in precipitation occur during the 'HS' case.

To understand the spatial distribution of energy budget terms, I plot map-views of select terms of the energy budget 2.1 For convenience of interpretation, the negative of divergence, i.e. convergence, is plotted. In this way, like the other energy budget terms, positive values of $-\nabla \cdot \mathbf{f}$ indicate sources of energy to the atmospheric column. The $F_{T O A}($ Figure 2.10) map-view shows that there there are regions that have a positive energy flux (more energy entering the column than leaving) and regions with a negative net flux (more energy leaving the column than entering). Regions of negative $F_{T O A}$ generally correspond with areas with high initial snowcover (refer to Figure 2.4 for each scenario's corresponding initial snowcover map). The mountainous regions in the Southeast region of the domain during the HS scenario display the most negative TOA radiation flux. This same region also shows the most negative surface energy flux at the surface and the most positive convergence of horizontal energy transport.

Figure 2.12 shows the domain wide average (bar) and standard deviation (whiskers) of energy budget terms. There is a significant reduction in $S W_{T O A}$ yet only a modest increase in $L W_{T O A}$ with increasing initial snowcover. Correspondingly, the top of atmosphere shortwave radiation balance is reduced, and the convergence of horizontal energy transport increases from the NS case to the HS SNOWMOD case.

To further examine the role of snow forcings on the divergence of horizontal energy transport, I calculate the difference between the 'HS' and 'LS' model scenarios (Figure 2.13) for all timesteps and grid cells across the model run. Blue regions are 

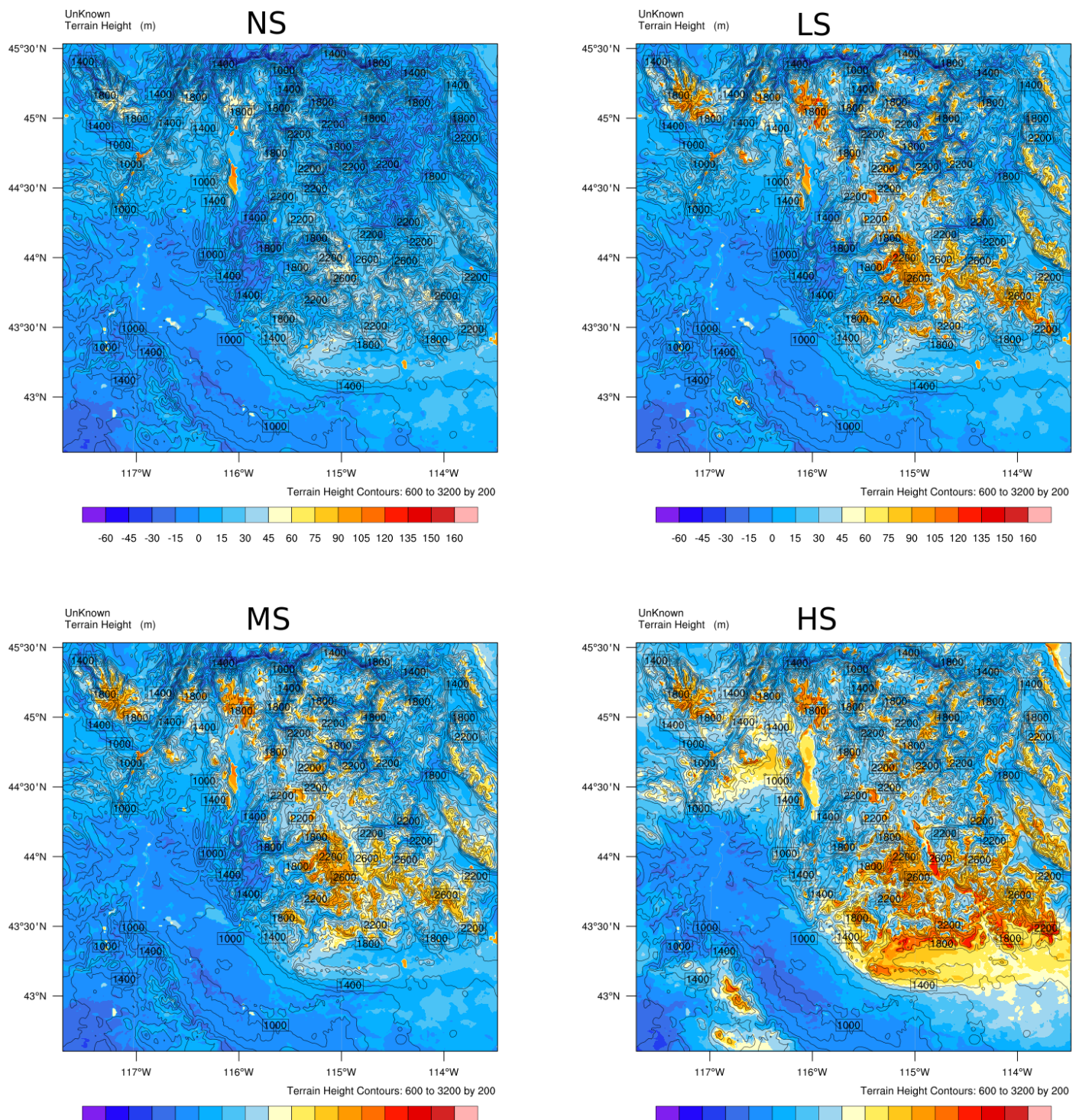

$60 \begin{array}{cccccccccccccccc}-45 & -30 & -15 & 0 & 15 & 30 & 45 & 60 & 75 & 90 & 105 & 120 & 135 & 150 & 160\end{array}$

$\begin{array}{llllllllllllllll}-60 & -45 & -30 & -15 & 0 & 15 & 30 & 45 & 60 & 75 & 90 & 105 & 120 & 135 & 150 & 160\end{array}$

Figure 2.9: Average horizontal energy transport $(-\nabla \cdot \mathbf{f})$ for SNOWMOD scenarios (clockwise from top left) NS, LS, HS, MS. Units are $w / m^{2}$ 

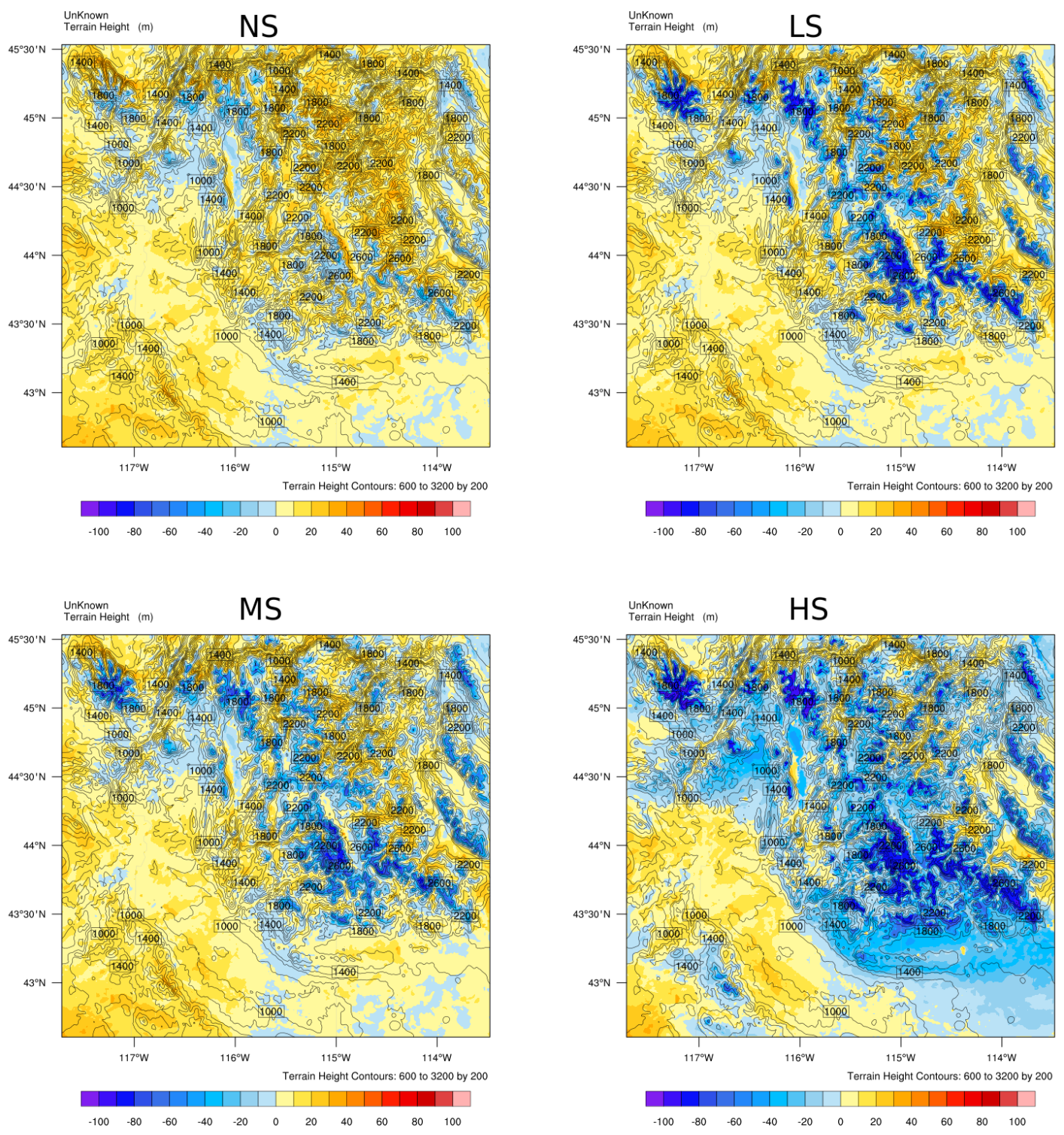

Figure 2.10: Top of Atmosphere Radiation $\left(F_{T O A}\right)$ flux for SNOWMOD scenarios (clockwise from top left) NS, LS, HS, MS. Units are $w / m^{2}$ 

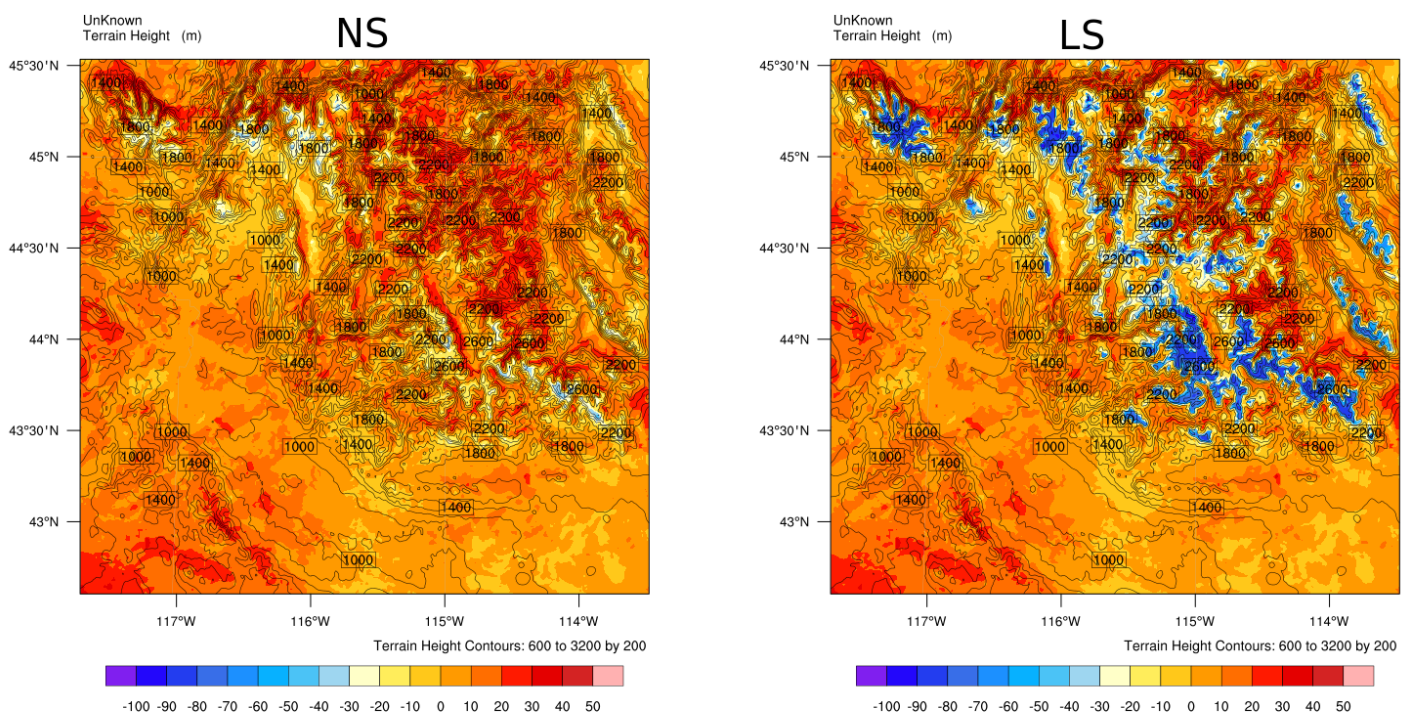

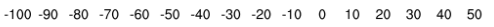
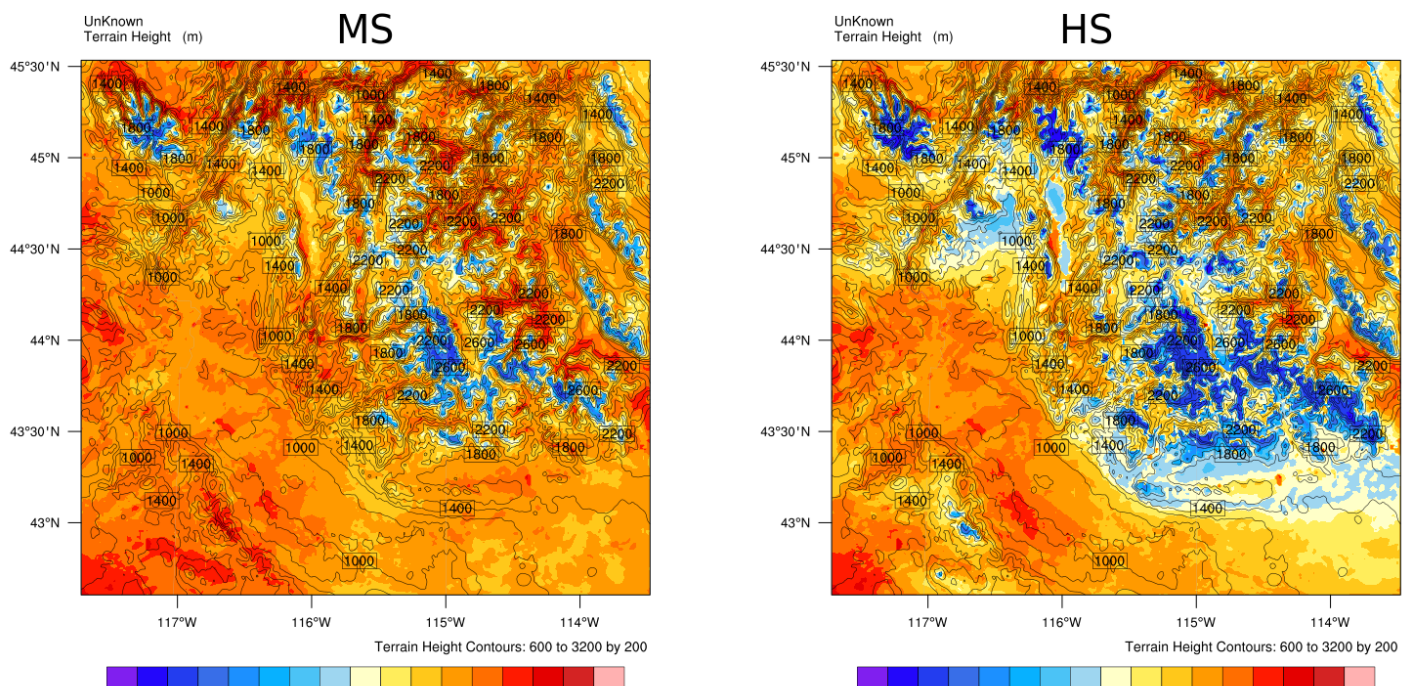

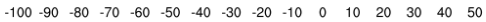

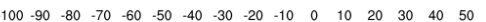

Figure 2.11: Surface Energy Balance $\left(F_{S F C}\right)$ flux for SNOWMOD scenarios (clockwise from top left) NS, LS, HS, MS. Units are $w / m^{2}$ 


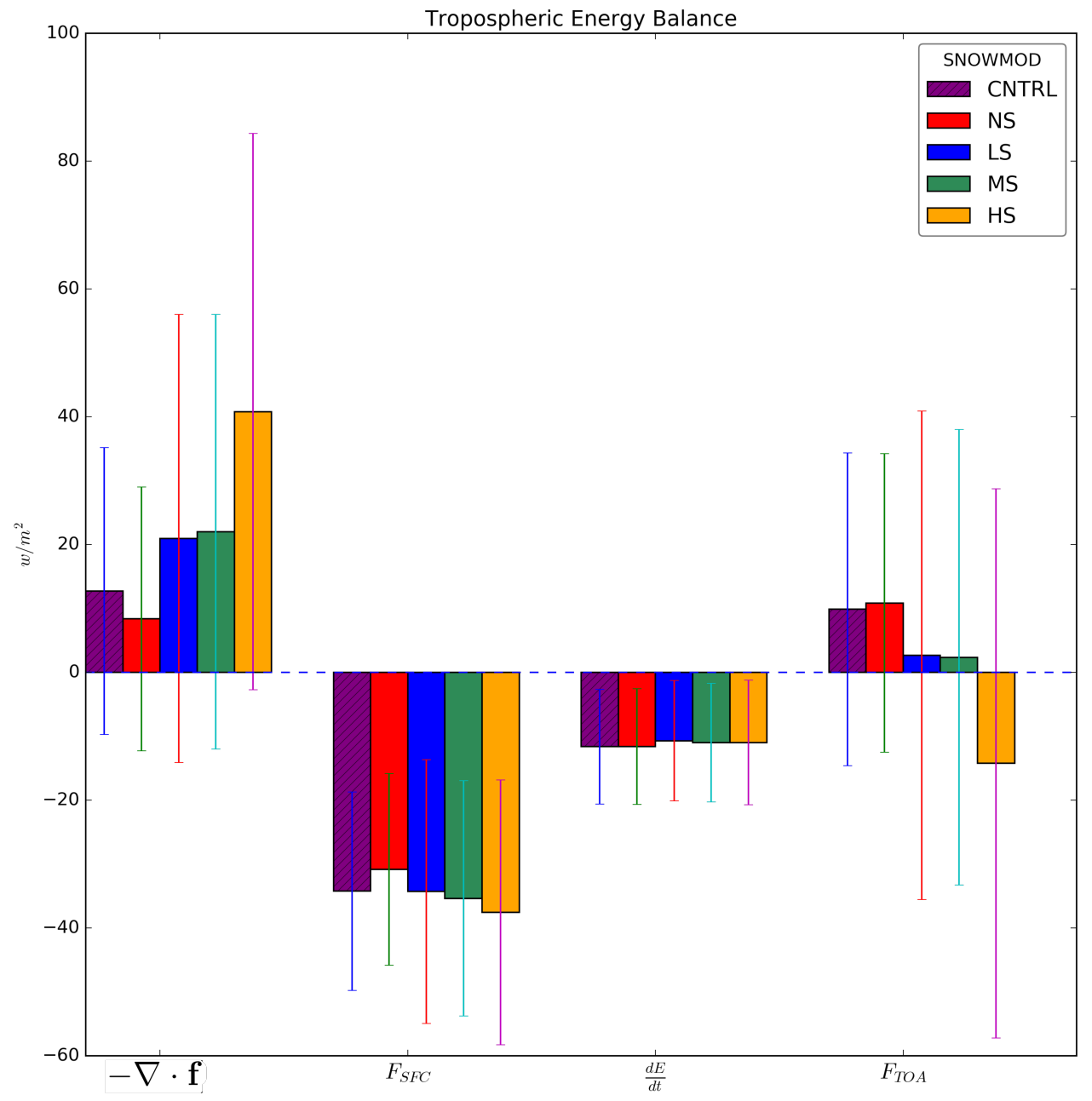

Figure 2.12: Domain Energy Budget Flux Terms for the 1998 AR event 
grid cells in which the HS case has greater snow covered area than the NS case; red regions are grid cells where neither the HS nor NS case are snow covered initially. Again, for the convenience of interpretation, I plot the negative of divergence $(-\nabla \cdot \mathbf{f})$, positive values of which indicate a source of energy to the atmospheric column. There is an approximately linear relationship between decreasing $\Delta\left(S W_{T O A}\right)$ and increasing $\Delta(-\nabla \cdot \mathbf{f})$, as well as an approximately linear relationship between decreasing sensible/latent heat terms and $\Delta(-\nabla \cdot \mathbf{f})$. For grid cells in which there has been no change in the initial snowcover between ensemble scenarios, the difference in $S W_{T O A}$ is small, and $\Delta(-\nabla \cdot \mathbf{f})$ is generally negative. Moreover, the same grid cells undergo increases in sensible/latent heat fluxes. Unlike $S W_{T O A}, L W_{T O A}$ increases only slightly with the additional presence of snow.

\section{Atmospheric Stability}

Snow covered area (SCA) and the average BV frequency of the lower 5 eta levels are differenced between all snow covered grid cells in SNOWMOD scenario HS and the corresponding grid cell in scenario NS for domain 2 (Figure 2.14), for every timestep for the duration of the model run. A one-sided t-test shows that the mean change in $\mathrm{BV}$ frequency is positive and significantly different than 0 for both binned $\Delta \mathrm{SCA}$ ranges at the $<.005$ level. Given that the comparison is between the HS and NS

scenarios, the latter of which is totally snow-free initially, there are few grid cells in which $\triangle \mathrm{FSCA}$ is negative, and there is not a statistically significant relationship between a decrease in $\Delta$ SCA and stability. 

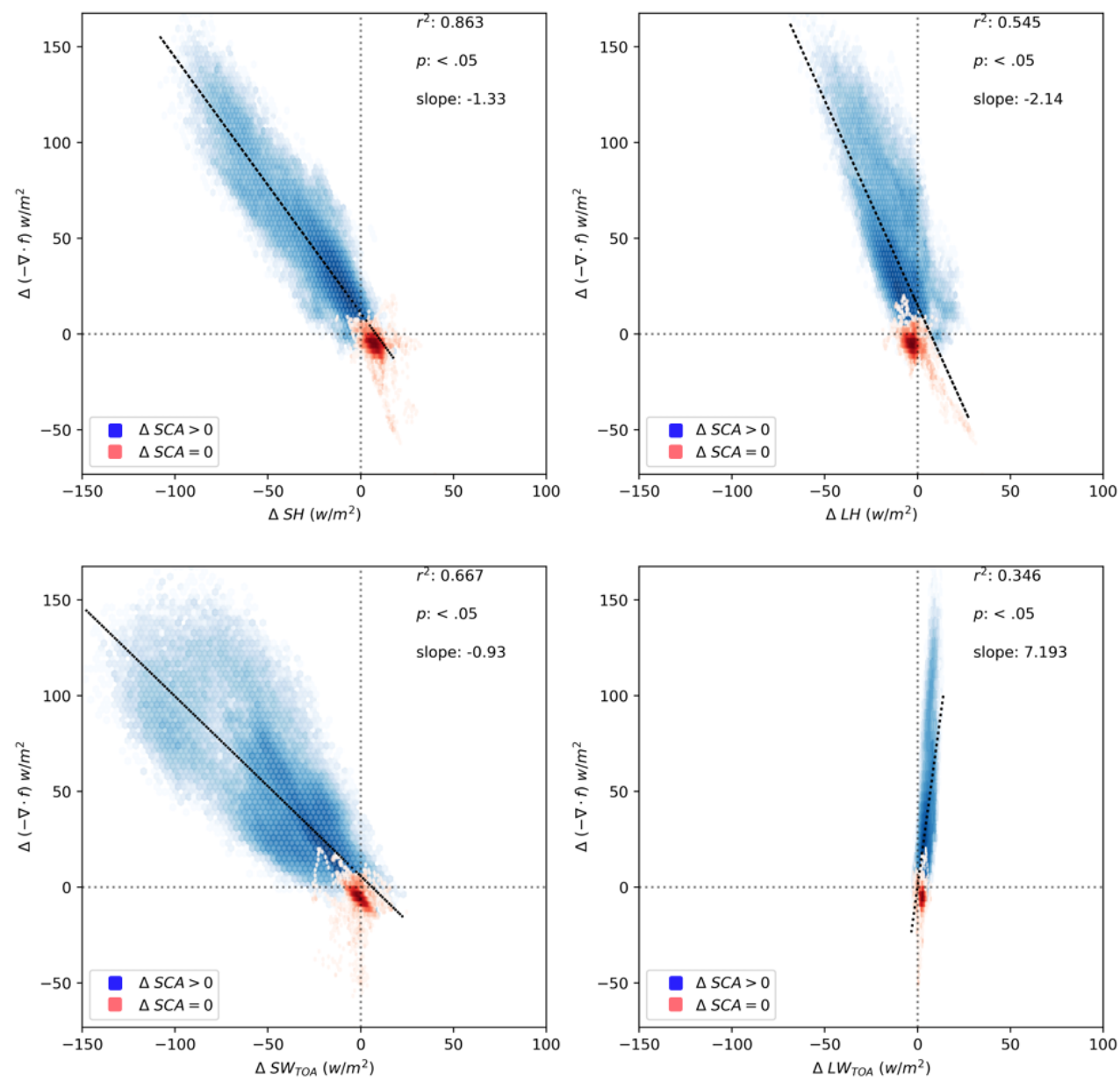

Figure 2.13: The difference between scenario HS and NS Energy Budget Terms versus $-\nabla \cdot \mathbf{f}$. Grid cells where there is no difference in initial snow covered area between HS and NS are red; Grid cells with higher initial snow in the HS scenario are blue. 


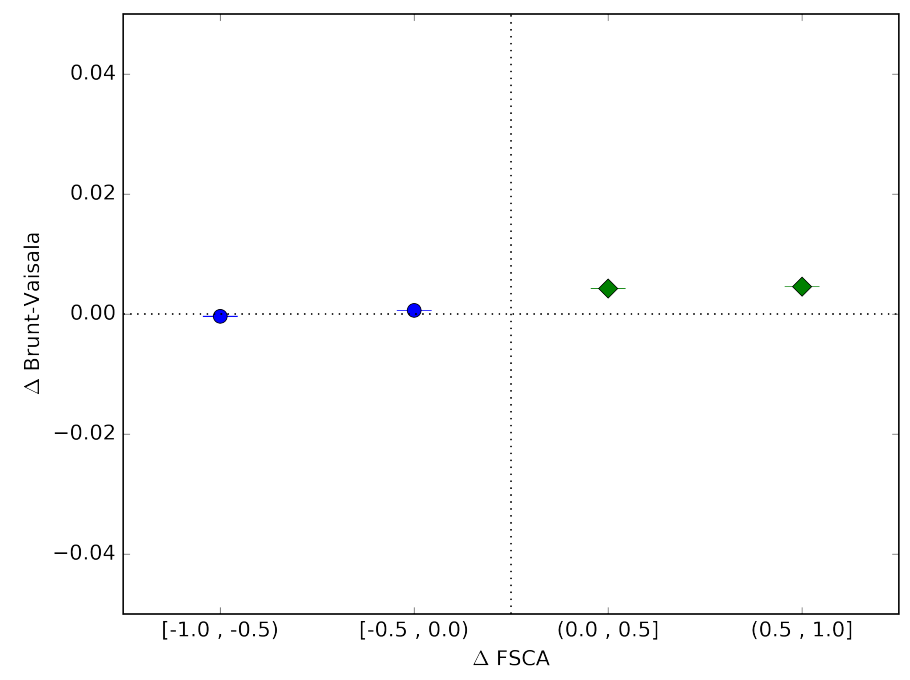

Figure 2.14: FSCA vs BV frequency D02

\subsubsection{Discussion}

Figure 2.12 and 2.13 shows that the divergence of horizontal energy transport $(\nabla \cdot \mathbf{f})$ is the primary mechanism through which reductions in top-of-atmosphere shortwave radiation $\left(S W_{T O A}\right)$ and turbulent energy exchanges $(\mathrm{LH}, \mathrm{SH})$ forced by the presence of snow are balanced. The reductions in $F_{T O A}$ forced by snowcover are primarily due to snow-albedo; increasing SCA increases the amount of shortwave radiation reflected from the land surface. Figure 2.13 demonstrates that snow forcing has non-local effects; even in grid cells where there is no change in snow covered area, energy is lost through horizontal energy transport, and the surface cools through sensible and latent heat exchange. In this way, the energy reflected over snow covered regions, or lost to the snow surface through melt, becomes balanced by advected energy from other, potentially over non-snowcovered regions. 
While snow has a higher emissivity than the other land surface materials, snow temperatures are constrained to a maximum temperature of $0^{\circ} \mathrm{C}$. For high snow versus low snow cases, the average emissivity may be higher in the former, but surface temperatures are lower, meaning there is a net decrease in outgoing longwave radiation. Figure 2.13 shows that there is in fact a small increase in $L W_{T O A}$ flux at the top of the atmosphere forced by increased snowcover; this is consistent with colder snow temperatures radiating less energy relative to non snow covered surfaces.

Figure 2.7 shows that increasing initial snowcover within the domain leads to the greater variability in frozen precipitation anomaly (SNOWMOD - Control). The largest differences are primarily in mountainous regions of complex topography, where orographic precipitation enhancement is in effect. Compared to the snowcover anomalies, the precipitation anomalies between SNOWMOD members are smaller in magnitude and occur over smaller, patchier regions.

Domain wide, the differences in total, domain wide precipitation is small between SNOWMOD experiments and the control (Table 2.1), on the order of three or fewer percentage points. Moreover, the ratios of snow/rain do not change significantly between SNOWMOD experiments, showing that the in some places large $\left(+5^{\circ} \mathrm{C}\right)$ change in surface air temperatures caused by anomalous snowcover (not shown) is not sufficient to alter the phase of falling precipitation. However, it is worth noting that hydrometeor phase in complex topography is difficult and poorly modeled in general. The differences in total accumulated precipitation caused by changing initial snowcover are likely due to cooling from the snow surfaces, which modify the atmospheric temperature structure and increase static stability. Figure 2.14 shows 
that increased SCA has a statistically significant effect on increasing the stability of the lower atmosphere. Calculating the Froude number (or Non-Dimensional Mountain Height) is beyond the scope of this paper and is not straightforward to compute in the case of 3-D flow across regions of complex topography. However, the BV frequency is the denominator of the Froude number; assuming incoming wind speed stays the same, and the safe assumption that mountain height remains constant, these results indicate that snow may tend to promote conditions leading to a lower Froude number more characteristic of blocking conditions, where airmasses are inhibited from crossing mountain barriers. The small changes in atmospheric stability between model scenarios, captured by the BV frequency, likely explain the differences in precipitation distributions across the complex terrain. Moreover, changes in wind direction and speed likely explain the fact that snow has a greater spatial variablity than rain. Snow has a slower fall speed than rain (and is modeled in $\mathrm{WRF}$ ), so there is more time for it to be advected by wind as it falls. Model configuration and choice of microphysics, planetary boundary and surface layer schemes may change the results of this research significantly. The effects of clouds on radiation exchanges are included in WRF, but are not analyzed separately in this research. Nevertheless it is evident that even during cloudy conditions associated with periods of AR activity, the effects of surface snow albedo still exerts a large control on the radiative budget. 


\subsubsection{Conclusions}

I demonstrate that during inland AR events in the central Idaho mountains, snow cover impacts the distribution of precipitation, but not the total domain wide magnitude, and forces atmospheric motions that balance reductions in shortwave top of atmosphere radiation and energy lost to warm snowpacks. These findings match the results of Letcher and Minder (2015) who found that horizontal energy transport effectively dampens the snow-albedo-feedback, manifest in an approximately linear relationship between reduction TOA shortwave radiation forced by the SAF and a increased $-\nabla \cdot \mathbf{f}[27]$. Changes in stability forced by cooling from snowcover, which modifies the low level flow around terrain, is the likely mechanism that explains the spatial differences in total accumulated precipitation between SNOWMOD experiments.

This research demonstrates that snow-atmosphere processes are not only important from a global or regional climate perspective, but may also be a significant forcing in AR systems and an element of numerical weather prediction. Following this observation, this research highlights the need for greater understanding of snow processes in mountainous regions in complex terrain; the snow albedo feedback is recognized (by this work and others) as the primary mechanism through which snow forces the atmosphere, yet, measurements of snow albedo in areas of mountainous terrain, in addition to the more well known deficiencies in spatially distributed SWE and SCA, are problematic and poorly constrained. 


\section{$2.3 \quad$ Summary}

Seasonal snow is among the most variable land-surface components in the Northern Hemisphere in both space and time. Snow has a high albedo, low thermal conductivity, high emissivity, and high latent heat of melting, that impacts weather and climate across scales. This study tested the role of snowcover forcing during central Idaho Atmospheric River events using the WRF numerical weather prediction model coupled with the Noah-MP LSM, configured at a $1 \mathrm{~km}$ convection permitting spatial scale. A March 1998 Atmospheric river was modeled with six different snow cover initial states, representing a range of possible snowcover conditions. The results demonstrate that 1) reductions in TOA shortwave radiation forced by by snow-albedo and sensible/latent heat directed into snow drive atmospheric motions, 2) snowcover has a stabilizing effect on the lower atmosphere, and 3) initial snowcover influences the geographic distribution of precipitation accumulation during AR events, but has relatively little impact on the total magnitude of precipitation summed across the entire domain. The presence of snow can have non-local influences that drive cooling even in non-snow covered areas.

The results of this work suggest that snowpack may be a significant land surface variable to constrain for the modeling and forecasting of precipitation. Snow, and particularly snow-albedo, are poorly constrained variables in mountainous terrain, and this reseach underscores the need for better remote sensing approaches for measuing snow albedo, snow extent, and snow water equivalent. This research also underscores the need for increased understanding of snow's role in the regional climate system, for current climates and future climate regimes. 


\section{REFERENCES}

[1] Michael A Alexander, James D Scott, Dustin Swales, Mimi Hughes, Kelly Mahoney, and Catherine A Smith. Moisture pathways into the us intermountain west associated with heavy winter precipitation events. Journal of Hydrometeorology, 16(3):1184-1206, 2015.

[2] Richard Ley Armstrong and Eric Brun. Snow and climate. Physical Processes, Surface Energy Exchange and Modeling. Cambridge University Press, Cambridge, UK, 2008.

[3] Donald G Baker, David L Ruschy, Richard H Skaggs, and David B Wall. Air temperature and radiation depressions associated with a snow cover. Journal of Applied Meteorology, 31(3):247-254, 1992.

[4] Anjuli S Bamzai and J Shukla. Relation between eurasian snow cover, snow depth, and the indian summer monsoon: An observational study. Journal of Climate, 12(10):3117-3132, 1999.

[5] Timothy P Barnett, L Dümenil, U Schlese, El Roeckner, and Mojib Latif. The effect of eurasian snow cover on regional and global climate variations. Journal of the Atmospheric Sciences, 46(5):661-686, 1989. 
[6] Ana Paula Barros and Dennis P Lettenmaier. Dynamic modeling of orographically induced precipitation. Reviews of geophysics, 32(3):265-284, 1994.

[7] Henry F Blanford. On the connexion of the himalaya snowfall with dry winds and seasons of drought in india. Proceedings of the Royal Society of London, $37(232-234): 3-22,1884$.

[8] Judah Cohen and Dara Entekhabi. Eurasian snow cover variability and northern hemisphere climate predictability. Geophysical Research Letters, 26(3):345-348, 1999.

[9] Judah Cohen and Justin Jones. A new index for more accurate winter predictions. Geophysical Research Letters, 38(21), 2011.

[10] Judah Cohen and David Rind. The effect of snow cover on the climate. Journal of Climate, 4(7):689-706, 1991.

[11] Judah Cohen, Kazuyuki Saito, and Dara Entekhabi. The role of the siberian high in northern hemisphere climate variability. Geophysical Research Letters, 28(2):299-302, 2001.

[12] William D Collins, Philip J Rasch, Byron A Boville, James J Hack, James R McCaa, David L Williamson, Bruce P Briegleb, Cecilia M Bitz, Shian-Jiann Lin, and Minghua Zhang. The formulation and atmospheric simulation of the community atmosphere model version 3 (cam3). Journal of Climate, 19(11):2144-2161, 2006. 
[13] William Ryan Currier, Theodore Thorson, and Jessica D Lundquist. Independent evaluation of frozen precipitation from wrf and prism in the olympic mountains. Journal of Hydrometeorology, 18(10):2681-2703, 2017.

[14] Michael Dettinger. Climate change, atmospheric rivers, and floods in californiaa multimodel analysis of storm frequency and magnitude changes. JAWRA Journal of the American Water Resources Association, 47(3):514-523, 2011.

[15] Andrew W Ellis and Daniel J Leathers. Analysis of cold airmass temperature modification across the us great plains as a consequence of snow depth and albedo. Journal of Applied Meteorology, 38(6):696-711, 1999.

[16] Matt; Flores, Alejandro; Masarik and Katelyn Watson.

[17] Luis Gimeno, Raquel Nieto, Marta Vázquez, David A Lavers, Ricardo M Trigo, Olivia Martius, and Helen Dacre. Atmospheric rivers: a mini-review.

[18] Bin Guan, Noah P Molotch, Duane E Waliser, Eric J Fetzer, and Paul J Neiman. Extreme snowfall events linked to atmospheric rivers and surface air temperature via satellite measurements. Geophysical Research Letters, 37(20), 2010.

[19] Bin Guan and Duane E Waliser. Detection of atmospheric rivers: Evaluation and application of an algorithm for global studies. Journal of Geophysical Research: Atmospheres, 120(24):12514-12535, 2015.

[20] Bin Guan, Duane E. Waliser, F. Martin Ralph, Eric J. Fetzer, and Paul J. Neiman. Hydrometeorological characteristics of rain-on-snow events associated with atmospheric rivers. Geophysical Research Letters, 2016. 
[21] Bin Guan, Duane E Waliser, F Martin Ralph, Eric J Fetzer, and Paul J Neiman. Hydrometeorological characteristics of rain-on-snow events associated with atmospheric rivers. Geophysical Research Letters, 43(6):2964-2973, 2016.

[22] David S Gutzler and Jessica W Preston. Evidence for a relationship between spring snow cover in north america and summer rainfall in new mexico. Geophysical Research Letters, 24(17):2207-2210, 1997.

[23] Douglas G Hahn and J Shukla. An apparent relationship between eurasian snow cover and indian monsoon rainfall. Journal of the Atmospheric Sciences, 33(12):2461-2462, 1976.

[24] Benjamin J Hatchett, Susan Burak, Jonathan J Rutz, Nina S Oakley, Edward H Bair, and Michael L Kaplan. Avalanche fatalities during atmospheric river events in the western united states. Journal of Hydrometeorology, 18(5):1359$1374,2017$.

[25] Mimi Hughes, Alex Hall, and Robert G Fovell. Blocking in areas of complex topography, and its influence on rainfall distribution. Journal of the Atmospheric Sciences, 66(2):508-518, 2009.

[26] Kyoko Ikeda, Roy Rasmussen, Changhai Liu, David Gochis, David Yates, Fei Chen, Mukul Tewari, Mike Barlage, Jimy Dudhia, Kathy Miller, et al. Simulation of seasonal snowfall over colorado. Atmospheric Research, 97(4):462-477, 2010. 
[27] Theodore W Letcher and Justin R Minder. Characterization of the simulated regional snow albedo feedback using a regional climate model over complex terrain. Journal of Climate, 28(19):7576-7595, 2015.

[28] L Ruby Leung and Yun Qian. Atmospheric rivers induced heavy precipitation and flooding in the western us simulated by the wrf regional climate model. Geophysical research letters, 36(3), 2009.

[29] Sergey Y Matrosov. Characteristics of Landfalling Atmospheric Rivers Inferred from Satellite Observations over the Eastern North Pacific Ocean.

[30] Gregory J McCabe, Lauren E Hay, and Martyn P Clark. Rain-on-snow events in the western united states. Bulletin of the American Meteorological Society, 88(3):319-328, 2007.

[31] Thomas L Mote. On the role of snow cover in depressing air temperature. Journal of Applied Meteorology and Climatology, 47(7):2008-2022, 2008.

[32] Rebecca Mott, Megan Daniels, and Michael Lehning. Atmospheric flow development and associated changes in turbulent sensible heat flux over a patchy mountain snow cover. Journal of Hydrometeorology, 16(3):1315-1340, 2015.

[33] Paul J Neiman, F Martin Ralph, Gary A Wick, Jessica D Lundquist, and Michael D Dettinger. Meteorological characteristics and overland precipitation impacts of atmospheric rivers affecting the west coast of north america based on eight years of ssm/i satellite observations. Journal of Hydrometeorology, $9(1): 22-47,2008$ 
[34] Paul J Neiman, Lawrence J Schick, F Martin Ralph, Mimi Hughes, and Gary A Wick. Flooding in western washington: The connection to atmospheric rivers. Journal of Hydrometeorology, 12(6):1337-1358, 2011.

[35] Reginald E Newell, Nicholas E Newell, Yong Zhu, and Courtney Scott. Tropospheric rivers?-a pilot study. Geophysical research letters, 19(24):2401-2404, 1992.

[36] Guo-Yue Niu, Zong-Liang Yang, Kenneth E Mitchell, Fei Chen, Michael B Ek, Michael Barlage, Anil Kumar, Kevin Manning, Dev Niyogi, Enrique Rosero, et al. The community noah land surface model with multiparameterization options (noah-mp): 1. model description and evaluation with local-scale measurements. Journal of Geophysical Research: Atmospheres, 116(D12), 2011.

[37] David F Porter, John J Cassano, and Mark C Serreze. Analysis of the arctic atmospheric energy budget in wrf: A comparison with reanalyses and satellite observations. Journal of Geophysical Research: Atmospheres, 116(D22), 2011.

[38] F Martin Ralph, Paul J Neiman, Gary A Wick, Seth I Gutman, Michael D Dettinger, Daniel R Cayan, and Allen B White. Flooding on california's russian river: Role of atmospheric rivers. Geophysical Research Letters, 33(13), 2006.

[39] Roy Rasmussen, Changhai Liu, Kyoko Ikeda, David Gochis, David Yates, Fei Chen, Mukul Tewari, Michael Barlage, Jimy Dudhia, Wei Yu, et al. Highresolution coupled climate runoff simulations of seasonal snowfall over colorado: a process study of current and warmer climate. Journal of Climate, 24(12):30153048, 2011. 
[40] Gerard H Roe. Orographic precipitation. Annu. Rev. Earth Planet. Sci., 33:645$671,2005$.

[41] Jonathan J Rutz, W James Steenburgh, and F Martin Ralph. Climatological characteristics of atmospheric rivers and their inland penetration over the western united states. Monthly Weather Review, 142(2):905-921, 2014.

[42] Jonathan J Rutz, W James Steenburgh, and F Martin Ralph. The inland penetration of atmospheric rivers over western north america: A lagrangian analysis. Monthly Weather Review, 143(5):1924-1944, 2015.

[43] Suranjana Saha and Shrinivas Moorthi.

[44] W James Shuttleworth. Terrestrial hydrometeorology. John Wiley \& Sons, 2012.

[45] William C Skamarock, Joseph B Klemp, Jimy Dudhia, David O Gill, Dale M Barker, Wei Wang, and Jordan G Powers. A description of the advanced research wrf version 2. Technical report, National Center For Atmospheric Research Boulder Co Mesoscale and Microscale Meteorology Div, 2005.

[46] Dustin Swales, Mike Alexander, and Mimi Hughes. Examining moisture pathways and extreme precipitation in the us intermountain west using selforganizing maps. Geophysical Research Letters, 43(4):1727-1735, 2016.

[47] Gregory Thompson, Paul R Field, Roy M Rasmussen, and William D Hall. Explicit forecasts of winter precipitation using an improved bulk microphysics scheme. part ii: Implementation of a new snow parameterization. Monthly Weather Review, 136(12):5095-5115, 2008. 
[48] Duane Waliser and Bin Guan. Extreme winds and precipitation during landfall of atmospheric rivers. 2017.

[49] John E Walsh and Becky Ross. Sensitivity of 30-day dynamical forecasts to continental snow cover. Journal of Climate, 1(7):739-754, 1988.

[50] John E Walsh, David R Tucek, and Miriam R Peterson. Seasonal snow cover and short-term climatic fluctuations over the united states. Monthly Weather Review, 110(10):1474-1486, 1982.

[51] Melissa L Wrzesien, Tamlin M Pavelsky, Sarah B Kapnick, Michael T Durand, and Thomas H Painter. Evaluation of snow cover fraction for regional climate simulations in the sierra nevada. International Journal of Climatology, $35(9): 2472-2484,2015$.

[52] Li Xu and Paul Dirmeyer. Snow-atmosphere coupling strength in a global atmospheric model. Geophysical Research Letters, 38(13), 2011. 


\section{APPENDIX A}

\section{ATMOSPHERIC RIVER LITERATURE REVIEW}




\section{A.1 Atmospheric River Review}

Atmospheric rivers $(\mathrm{AR})$ have received considerable attention during the past two and a half decades. Atmospheric Rivers were first identified by Newell, who, in a now seminal 1992 work, termed them "tropospheric rivers" [35]. AR are long (typically $>2000 \mathrm{~km})$ and narrow $(300-400 \mathrm{~km})$ corridors of enhanced water vapor that occur within the warm conveyor belt of extratropical cyclone systems. They are characterized by concentrated water vapor, typically greater than $2 \mathrm{~cm}$ of total precipitable water within $2 \mathrm{~km}$ of sea level, and strong winds [14]. AR are one of the primary mechanisms through which the atmosphere distributes water from the tropics and sub-tropics to the mid latitudes. The "river" analogy is apt, given that AR typically transport water vapor on the order of the world's largest river systems. $\mathrm{AR}$ are particularly significant in mountainous regions where orographic precipitation enhancement is in effect, and single events can contribute large fractions of the total annual snow accumulation in many snow-dominated regions [18]. The presence or absence of a handful of AR controls water year totals in the Sierra Nevada. AR are globally occurring and not particularly uncommon; at any given time, there are likely 5 or 6 AR systems active globally [17]. AR are identified either from satellite based measurements of integrated water vapor (IWV) or integrated vapor transport (IVT), which is a function of specific humidity, zonal and meridional wind speed [19].

$\mathrm{AR}$ are significant in terms of both water resources and natural hazards. Numerous studies document the relationship between AR, extreme precipitation, and flooding in the Western United States, and recent research demonstrates a link between AR and avalanche fatalities [29] [24]. Guan (2010) showed that between 30-40 
$\%$ of SWE accumulation in their Sierra Nevada study domain between water years 2004-10 occurred the day before or following an AR observation [18]. Rain-on-snow flooding is a primary mechanism of flood generation in the Western US [30], and it has been shown that AR are often the cause of such events. Guan et al 2016 show that between 1998 and 2014, AR are associated with $17 \%$ of precipitation events and $50 \%$ of rain-on-snow events in the Sierra Nevada [21]. Snow likely acts as an efficient conduit for overland flow, and the combination of advected and latent heat exchange into snowpack from warm rain causes intense melting and runoff generation. There are demonstrable connections between the incidence of AR and flooding in many watersheds [34]. In California's Russian River basin, all seven floods over an eight year period were assosciated with with landfalling AR events [38]. Understanding $\mathrm{AR}$ response to climate change is an area of ongoing inquiry. In theory, the water vapor carrying capacity of AR will likely increase at the clausius clapeyron rate of $7 \%$ per $\mathrm{K}$ of warming, likely meaning increased precipitation from AR events [17]. However, climate change's effects on global circulation patterns remains less clear. A study of California AR using seven different future-climate models suggest an increase in the length of $\mathrm{AR}$ season, maximum water vapor transport rate, and temperature increases for extreme AR events. [33]. More work is needed to assess possible changes in AR frequency.

The majority of AR research focuses on coastal regions, though AR are significant actors in the intermountain West. Rutz et al (2015) used an AR identification method and Snotel records to establish that between 25-30\% of cool season (NovApril) precipitation in the Southwest central Idaho mountains result from inland 
Atmospheric River events. Understanding the pathways of moisture through complex terrain is a relatively new field of study. [46]. In order to understand the dominant pathways of AR into the intermountain West, Alexander et al. used a combination of empirical orthogonal function analysis and back-trajectory analysis to demonstrate that the dominant moisture routes into the intermountain West are associated with topographic lows in the Sierra Nevada and Cascade ranges[1]. Rutz et al (2015) likewise find the same, including a moisture pathway through the Snake River plain. Rutz et al. find that integrated vapor transport (IVT) has a higher correlation with precipitation than integrated water vapor (IWV) alone, suggesting that not only precipitable water, but also incoming flow velocity is an important component of AR precipitation for this region [41].

Lueng et al (2009) used the Weather Research and Forecasting regional climate model to simulate several flood producing Atmospheric River events across the Western United states [28]. Their findings suggest that WRF reasonably well models orographically enhanced precipitation from AR events. They also speculate that while AR are typically characterized by moist-neutral static stability, small differences in stability between AR events influence the low-level atmospheric flow over terrain and precipitation. Specifically, the authors speculate that the Froude number, defined by stability and low-level wind speed, are a useful diagnostic for characterizing orographic precipitation enhancement during AR events. 


\section{A.2 Atmospheric River Detection}

To identify historic AR events that have impacted central Idaho, I employed an AR detection routine that follows the work of Guan [19]. I downloaded a subset of 6-hourly Climate Forecast System Reanalysis (CFSR) from 1979 - 2015 comprising specific humidity (kg water vapor/ kg air, abbreviated as Q), U (meridional) and V (zonal) wind velocity from NCAR's Research Data Archive [43]. The dataset is over 3TB in total. There are many different reanalysis products available, and with minor modifications the code could work for another dataset. The code uses an Integrated Vapor Transport (IVT) based identification threshold to define AR (Equation A.1). IVT is a vector quantity, defined as the inverse of gravity times the integral of specific

humidity $\mathrm{Q}$ ( $\mathrm{kg}$ water vapor/ $\mathrm{kg}$ air) times the horizontal wind vector $\mathbf{V}$, from the surface to the top of the atmosphere.

$$
\mathrm{IVT}=\frac{1}{g} \int_{P_{s} f c}^{P_{t} o p} Q \cdot \mathbf{V} d P
$$

The identification algorithm operates by first identifying regions of IVT that exceed the background transport. A given grid cell $i, j$ at time $t$ must exceed a fixed IVT threshold of $100 \mathrm{~kg} / \mathrm{m} / \mathrm{s}$, or the 85 th percentile of IVT from the period of record. The percentile maps are calculated by finding the 85th percentile of each grid cell for each month which as interpreted as a centered estimate at the middle of the month. Then, for a given day, the 85th percentile map is calculated by linearly interpolating between the current month grid and the next/previous month grid. Grid cells with lesser magnitudes than the fixed threshold are set to a null value. 


\begin{tabular}{|l|l|}
\hline Parameter & Value \\
\hline Location & $\begin{array}{l}\text { Northern Hemisphere Pa- } \\
\text { cific between } 30^{\circ} \text { and } 50^{\circ} \mathrm{N} .\end{array}$ \\
\hline Min. Length & $2000 \mathrm{~km}$ \\
\hline Max Width & $1000 \mathrm{~km}$ \\
\hline Min. Mean IVT & $250 \mathrm{~kg} / \mathrm{m} / \mathrm{s}$ \\
\hline $\begin{array}{l}\text { Poleward component of IVT } \\
\text { Magnitude }\end{array}$ & $50 \mathrm{~kg} / \mathrm{m} / \mathrm{s}$ \\
\hline
\end{tabular}

Figure A.1: AR Identification Criteria, based on Guan et al (2015)

Regions of contiguous grid cells that pass the threshold are grouped and assigned a common label using Python's Scipy 'skimage regionprops' object identification code. These regions are potential AR features, and subsequently a series of tests are performed to determine if they meet the criteria outlined in Table A.1. AR objects that meet the criteria are logged in a database. Overall, 3431 AR events intersecting the North American coast between 30 and 50N are identified between 1980 and 2010, the equivalent of roughly 7 per month. Maps of three select AR events are shown in Figure A.2. The color shading corresponds with the magnitude of the IVT vector, and the arrows show IVT direction.

\section{A.3 Summary and Conclusion}

Atmospheric rivers can cause disastrous flooding, landslides and avalanches, yet they also bring rain and snow necessary for many regional water supplies. Atmospheric Rivers area globally occurring phenomena and are not particularly rare- 5 or 6 are occurring at any time. Yet, the bulk of the research has focused on California's Sierra Nevada, where only a handful of AR per year often result in significant fractions 
of total precipitation accumulation. AR cause $25-30 \%$ of cool season precipitation in the central Idaho mountains and precipitation is highly correlated with mean IVT of the AR. [42][41]. The dominant AR tracks into the intermountain west are associated with topographic lows in the Sierra and Cascade mountain ranges. Modeling and observational studies suggest that the orientation of AR with respect to topography is an important mechanism that influences the intensity of orographic precipitation associated with AR, and that low level stability, and the Froude number, are important diagnostics of the orographic precipitation enhancement during AR events. 

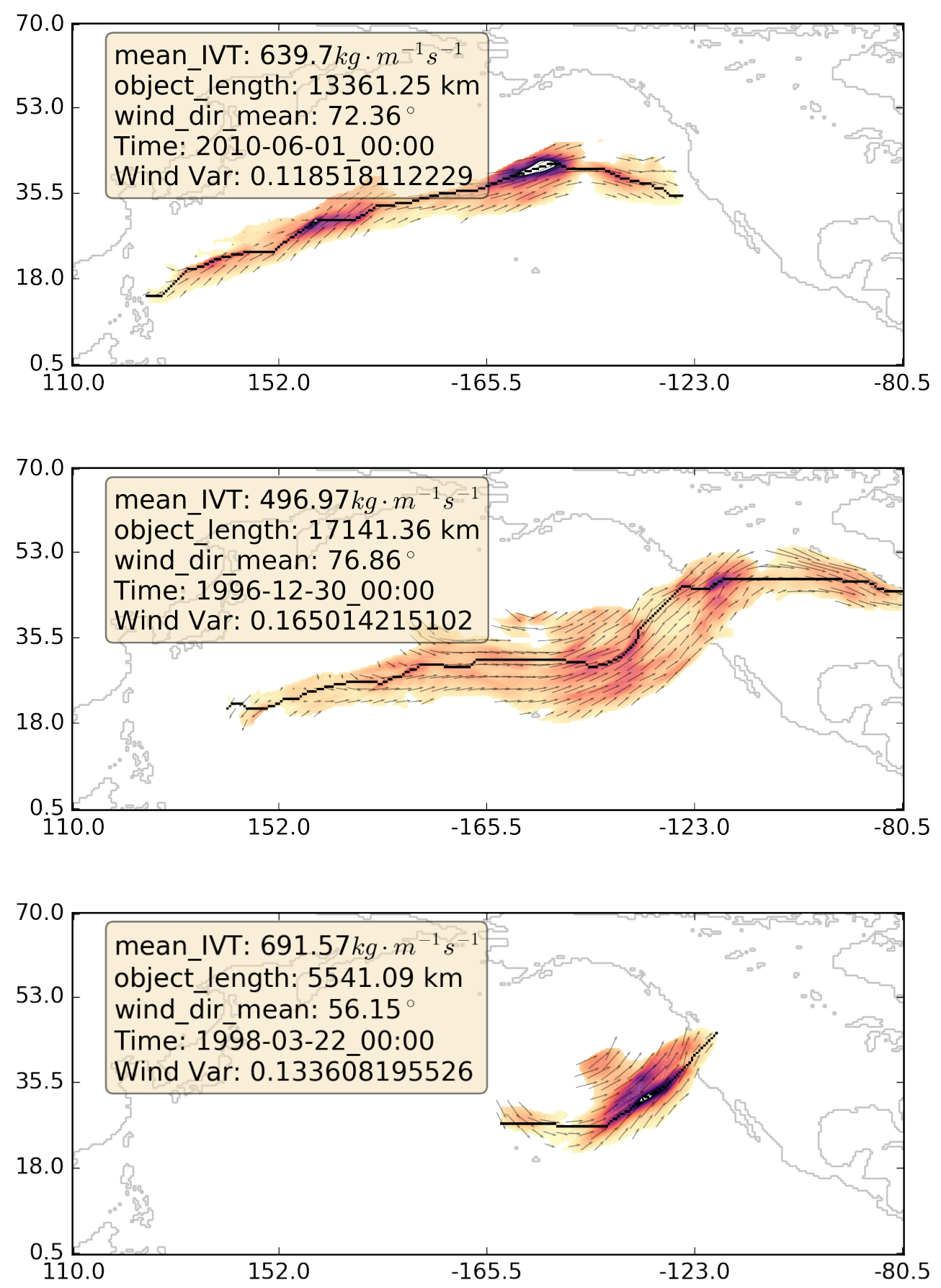

Figure A.2: A selection of AR events modeled in this thesis. Axes are lat/lon coordinates, color shading corresponds with the magnitude of IVT, and the arrows indicate IVT direction. Values in box refer to mean values of IVT, object length, wind direction, and wind direction variance. The black line is the object centerline. 